\title{
Universidad y patrones de género en el primer franquismo. Continuidades y rupturas en la enseñanza universitaria: alumnas, doctoras y profesoras
}

\author{
Helena SaAvedra Mitjans \\ Centre d'Estudis sobre Dictadures i Democràcies - Universitat Autònoma de Barcelona \\ (España) \\ orcid.org/0000-0003-4313-850
}

Presentación: 6 oct. 2018 | Aceptación: 2 nov. 2018 | Publicación: 15 dic. 2018

Cita recomendada: Saavedra Mitjans, Helena. 2018. «Universidad y patrones de género en el primer franquismo. Continuidades y rupturas en la enseñanza universitaria: alumnas, doctoras y profesoras». Dictatorships \& Democracies. Journal of History and Culture 6: 51-87. doi: https://dx. doi.org/ 10.7238/dd.voi6.3153.

Resumen: El objetivo de este artículo es analizar la presencia de las mujeres universitarias en el Distrito Universitario de Barcelona como estudio de caso desde dos perspectivas temporales distintas. Por un lado, se analiza en detalle la presencia de las alumnas y profesoras de la Universidad de Barcelona durante el período del primer franquismo (1939-1957). Por el otro, se presenta una visión de conjunto sobre la presencia de las mujeres, como alumnas, en la enseñanza superior a la largo del siglo xx (1917-1987). Desde la disciplina histórica, cuantificar y caracterizar quiénes eran las mujeres en distintas etapas cronológicas es esencial, primeramente, porque permite ampliar el conocimiento histórico sobre este objeto de estudio en España e ir más allá de las pioneras. Además, cubrir el vacío existente sobre esos primeros años de la dictadura resulta clave para poder unir las dos etapas históricas más estudiadas: el primer tercio del siglo xx y la etapa democrática posterior a la Transición. Solo reconstruyendo las continuidades y transformaciones que tuvieron lugar entre 1939 y 1957 e insertándolas en un contexto más global, se puede valorar si la instauración del nuevo régimen político supuso un cambio (y en qué grado) en las dinámicas de crecimiento de la población universitaria femenina y si la redistribución del alumnado entre las distintas facultades (preferencias de estudio) se modificó.

Palabras clave: mujeres, franquismo, universidad, Barcelona, alumnas, profesoras

\footnotetext{
* Las tesis que se defienden en este artículo fueron presentadas y debatidas en el Congreso Internacional «Mujeres y Enseñanza Superior. Un Siglo de historia de las mujeres en las Universidades», VIII Centenario de la Universidad de Salamanca, celebrado en Salamanca entre el 28 y el 30 de septiembre de 2017 .
} 


\section{University and Gender Dynamics in Barcelona University District (1939-1957).} Students, Doctors and Professors: (Dis)continuities in Higher Education in the 2oth Century

Abstract: This article aims to analyse the female presence at university through the case study of Barcelona University District from two different chronological perspectives. On the one hand, the presence of women, both as students and as professors, is analysed during the former period of General Franco's regime specifically. On the other hand, the study broadens out the dictatorship chronology in order to obtain a global perspective of the university female students in the 2oth century. From the historical perspective, quantify and qualify these women in different historical periods is crucial. There are many historical studies about the pioneers and presence/absence of women at university during the first third of the 2oth century, as well as sociological studies carried out after the dictatorship period. However, very little has been published specifically about the dictatorship time. Consequently, this article fills this chronological gap and allows to provide a global explanation of the phenomenon linking all the different periods. Indeed, the interest lies in knowing the role that General Franco's regime played regarding the female presence at university. For instance, if the growing dynamics were modified or not, or if the studies preferences changed, and if so, in what way. Only identifying what remained stable and what changed, we will be able to answer if the new regime meant to be a turning point or not as for women in academia.

Keywords: women, General Franco's regime, university, Barcelona, students, professors

Tanto a nivel nacional como internacional, existen numerosas y valiosas investigaciones que han analizado la presencia femenina en las instituciones de enseñanza universitaria desde finales del siglo xIx hasta la actualidad. ${ }^{1}$ No obstante, para el caso español, estos estudios se han centrado en determinados períodos cronológicos y políticos. Por un lado, son muy significativos los estudios de las primeras universitarias ${ }^{2}$ (las pioneras) durante las últimas décadas del siglo xix y el primer tercio del siglo xx. ${ }^{3}$ Por el otro, son abundantes los trabajos sobre mujeres y universidad

1 Para un exhaustivo estado de la cuestión sobre la temática mujeres y universidad en España, véase Ballarín Domingo (2010).

2 Por su carácter innovador en su momento y que contribuyó a abrir una nueva línea de investigación, hay que mencionar la obra de Flecha García (1996), además de la larga lista de publicaciones posteriores con relación a la temática mujeres y universidad.

3 Desde una perspectiva global del objeto de estudio mujeres universitarias, véase Vázquez Ramil (2012); Rodríguez López (2013); Cuesta Bustillo, De Prado Herrera y Rodríguez (2015); Del Val Valdivieso y Martínez Quinteiro (2015). Sobre las mujeres en las distintas etapas educativas a lo largo de la edad contemporánea, véase Ballarín Domingo (2001). Sobre la incorporación de las mujeres en las carreras científicas, véase Magallón Portolés (2010) y Pintos Barral (2016). 
para el período democrático posterior a la Transición y hasta la actualidad. ${ }^{4}$ Entre ambos extremos cronológicos, sin embargo, queda una larga etapa histórica sin estudiar. En efecto, es preciso iniciar o dar continuidad a recientes investigaciones sobre las mujeres en la universidad durante el régimen franquista (Santesmases 2000, Reparaz de la Serna 2015, Saavedra-Mitjans 2016). Concretamente, de los casi cuarenta años de dictadura, las primeras dos décadas son las grandes desconocidas en la historiografía española. ${ }^{5}$

El objetivo de este trabajo es analizar la presencia de las mujeres en la universidad entre 1939 y 1957, e insertar dicho período en un análisis global de la primera mitad del siglo xx. Para ello, se lleva a cabo un doble análisis temporal del fenómeno: primeramente, se presenta una visión de conjunto de la presencia de las mujeres en la enseñanza media y universitaria a lo largo del siglo xx (1917-1987). Posteriormente, en la segunda parte, el estudio se centra únicamente en el personal discente y docente universitario en una cronología más limitada, la primera etapa de la dictadura franquista. En ambos casos, el ámbito territorial donde se lleva a cabo la investigación es el Distrito Universitario de Barcelona (de ahora en adelante, DUB). ${ }^{6}$ Hasta 1968 , el único centro universitario existente en esta área territorial 7 era la Universidad de Barcelona (de ahora en adelante, UB). Así pues, hasta la creación de las universidades autónomas a finales de los sesenta, hablar de DUB es sinónimo de UB.

La elección de este distrito universitario (y en su defecto el centro universitario barcelonés) tiene una doble justificación. En primer lugar, es

4 En este caso, los estudios se han realizado desde otras disciplinas científicas, como la Sociología o las Ciencias de la Educación, o desde la historia de la educación. Sin ánimo de exhaustividad, algunas referencias: Borja i Solé (1983), C.N.I.E. (1988), García de León y García de Cortázar Nebreda (2001), Poy Castro (2009).

5 Sería inexacto no mencionar dos textos que abordan esta etapa: Canales (2012), Sanchidrián Blanco (2008). En ambos textos se presentan hipótesis interpretativas interesantes (y opuestas entre sí), pero quizás sean estudios excesivamente generalistas (la educación de las mujeres y la incorporación femenina al mundo profesional) y quedan un poco limitados por el corto espectro temporal que consideran.

6 Durante el período franquista existían 12 distritos universitarios.

7 El DUB era una unidad territorial, de naturaleza universitaria, que agrupaba los centros de enseñanza universitaria y las escuelas técnicas superiores de las provincias de Barcelona, Tarragona, Lleida, Girona y las Baleares. 
un ámbito territorial manejable que, además, al tener entidad propia como unidad administrativa, podía ser tratado como un estudio de caso. Es decir, buena parte de las interpretaciones que se extraen del estudio del DUB son extrapolables al conjunto estatal. El hecho de que no fuese el distrito universitario más importante cuantitativa y cualitativamente hablando hacía que la población universitaria tendiese a la estabilidad y a la homogeneidad (Montoro Romero 1981, 77-80, 147-151). ${ }^{8}$ Además, desde el punto de vista estructural, fueron pocos los cambios organizativos que sufrió el centro barcelonés: a las cinco facultades ya existentes, en el curso 1954-1955 se añadió una de nueva creación: la facultad de Ciencias Políticas y Económicas. El segundo elemento, y no por ello menos importante, que justificó trabajar sobre el DUB, fue el temor de no conseguir datos para la reconstrucción estadística de la población universitaria. Ante la tesitura de tener que completar vacíos documentales, recomponer un solo distrito era mucho más factible que el conjunto estatal (y tener que recopilar los datos de todos y cada uno de los 12 distritos existentes).

Finalmente, en el último apartado se analiza si con la instauración del nuevo régimen político franquista la evolución de la población estudiantil universitaria se modificó con respecto a la etapa anterior o, por el contrario, perpetuó las dinámicas ya existentes. El interés reside en explicar, desde la perspectiva de género, qué significó para las mujeres universitarias la instauración del Nuevo Estado. Ciertamente, el Nuevo Estado públicamente defendía que se debía:

Encauzar la gran corriente de estudiantes apartándolas de la pedantería feminista de bachilleras y universitarias, que deben ser la excepción, orientándolas hacia su propio magnífico ser femenino, que se desarrolla en el hogar. (Pemartín Sanjuán 1937, 142) ${ }^{9}$

8 Por un lado, la amplia oferta universitaria hacía que los residentes en las cinco provincias no tuvieran que cambiar de distrito para estudiar en la universidad (con la excepción de Veterinaria, todas las otras facultades ya estaban creadas). Por el otro, Barcelona no era el primer destino para los estudiantes que debían cambiar de distrito. La primera opción generalmente era ir a Madrid. Así, a pesar de que Barcelona era el "segundo distrito", no fue un polo de atracción tan fuerte como sí lo fue Madrid. Tampoco era un distrito tan cerrado o minoritario como podían ser Murcia o La Laguna.

9 Las opiniones de José Pemartín son ampliamente citadas, no solo por la claridad con que expresa sus posturas, sino porque ejerció un peso fundamental en la reorganización del sistema edu- 
Pero una cosa era el discurso oficial, permanente, incesante y completamente excluyente; y otra, el grado de efectividad en la práctica. Como muestran los gráficos reproducidos en este artículo, el número de universitarias no decreció con la instauración de la dictadura. Pero que la tendencia general no decreciera no significa que no hubiera cambios internos. Aquí se analiza si las tendencias de crecimiento, de distribución y de preferencias de estudio de la población universitaria entre las facultades se transformaron, y si fue así, ¿cómo fueron esos cambios? Solo si es posible reconstruir las (dis)continuidades que tuvieron lugar entre $1939 \mathrm{y}$ 1957, se podrán rebatir o reforzar ciertas hipótesis de trabajo. Esto es: en cuanto a las mujeres universitarias y su progresiva inclusión en la enseñanza universitaria, ¿el franquismo fue un punto y aparte respecto a la tendencia histórica anterior?

Antes de proceder al análisis, es preciso hacer algunas puntualizaciones respecto a los datos que se recogen en las siguientes páginas. En cuanto a la población estudiantil, la fuente documental utilizada ha sido el Anuario Estadístico de España ${ }^{10}$ del Instituto Nacional de Estadística. De los distintos datos recogidos en estos anuarios, se optó por contabilizar los datos de matrícula, ya que eran los que ofrecían una serie histórica más completa. ${ }^{11}$ Con relación al profesorado, ha sido necesario utilizar distintas fuentes documentales para reconstruir la composición de las plantillas docentes. Los datos que ofrecían los anuarios estadísticos eran limitados, así que se completaron con otros dos fondos documentales: la obra Estadística de la Enseñanza en España ${ }^{12}$ y las Memorias de la Universidad de Barcelona. ${ }^{13}$ La Estadística de la Enseñanza en España también fue reali-

cativo franquista. En 1938 fue nombrado jefe del Servicio Nacional de Enseñanza Superior y Media y, posteriormente, formó parte de la Dirección General del Ministerio de Educación, ejerciendo como director general de Educación Secundaria.

10 Referencia: Fondo INEbase/Historia. El anuario se puede consultar digitalmente en el siguiente enlace: http://www.ine.es/inebaseweb/libros.do? tntp $=25687$.

11 Se recogían otros datos también, por ejemplo: número de títulos expedidos, número de graduados y/o licenciados, número de alumnos que terminan los estudios, entre otros.

12 A lo largo del período esta colección adoptó distintas denominaciones: Estadística de la Enseñanza en España o Estadística de la Enseñanza superior en España. Esos cambios no afectaron al contenido. No son consultables digitalmente.

13 Para la etapa del primer franquismo se han localizado únicamente dos ediciones (Universitat de Barcelona 1950 y 1956). Hubiera sido interesante poder consultar los libros de matrículas para 
zada por el Instituto Nacional de Estadística; la diferencia respecto a los anuarios es que estos eran más completos: incluían un registro de datos provinciales, distinguían por sexo, por distritos, por facultades y por categoría profesional académica ocupada.

\section{Siglo $x x$, una visión de conjunto}

\section{Enseñanza media ${ }^{14}$}

Pese a que la enseñanza universitaria es el objeto de estudio principal de este artículo, conviene hacer algunas consideraciones sobre la etapa educativa precedente: la enseñanza media. Conocer qué ocurrió en esta etapa previa nos indica el punto de partida sobre el cual las mujeres accedieron o pudieron acceder a la universidad. Los gráficos que se presentan a continuación muestran la evolución de la matrícula en los cursos de bachillerato entre 1917 y $1987 .{ }^{15}$

Los datos representados en el gráfico 1 sobre la distribución porcentual alumnas-alumnos permiten identificar, por lo menos, dos fases de redistribución distintas. En la primera etapa, de 1917 a 1941, la diferencia porcentual tendía a reducirse progresivamente. Si al principio de siglo la relación alumnas-alumnos era un 8\% - 92\%, en 1941 esa proporción cambió a $35 \%-65 \%$.

A partir de ese momento, se iniciaba una nueva fase redistributiva con características distintas y que cronológicamente se mantuvo hasta 1967 (que se pueda documentar estadísticamente). En esta ocasión lo definito-

poder añadir otra fuente como referencia de contraste, pero estos están ilocalizables o perdidos en el Archivo Histórico de la Universidad de Barcelona.

14 En este apartado la unidad territorial sobre la cual se analiza el alumnado también es el DUB, a pesar de que el origen de dicha categoría espacial sea universitaria.

15 Sobre las transformaciones del bachillerato en las distintas etapas políticas a lo largo del siglo $\mathrm{xx}$, hay que mencionar que, con anterioridad al régimen franquista, el bachillerato se cursaba de los 14 a los 17 años. Entre 1938 y 1953 se denominó "Bachillerato Unificado" (BU) y comprendía de los 11 a los 17 años (siete cursos) y al finalizar se hacía un Examen de Estado. En sustitución del BU se creó el bachillerato medio y superior universitario, que se dividía en cuatro y dos cursos, respectivamente. Para acceder a la universidad era necesario hacer el curso preuniversitario (PREU), de un año de duración. En 1972 se introdujeron nuevos cambios y se creó el Bachillerato Unificado Polivalente (BUP), que comprendía de los 14 a los 16 años, tres cursos, y al finalizar se debía hacer el Curso de Orientación Universitaria (COU). 
rio era su carácter estático. La distribución porcentual permaneció prácticamente invariable: si en 1941 el porcentaje de estudiantes mujeres era un 34\%, en 1957 no eran más de un 37\% del total, apenas se modificó. En 1967 la proporción se alteró muy levemente, llegando a un 39\%. Este rasgo inmovilista nos lleva a constatar que, en términos relativos, durante buena parte de la etapa franquista no hubo un incremento significativo de mujeres en la etapa de la enseñanza media. ${ }^{16}$

\section{Gráfico 1. Distribución porcentual del alumnado de Enseñanza Media, DUB 1917-1987}

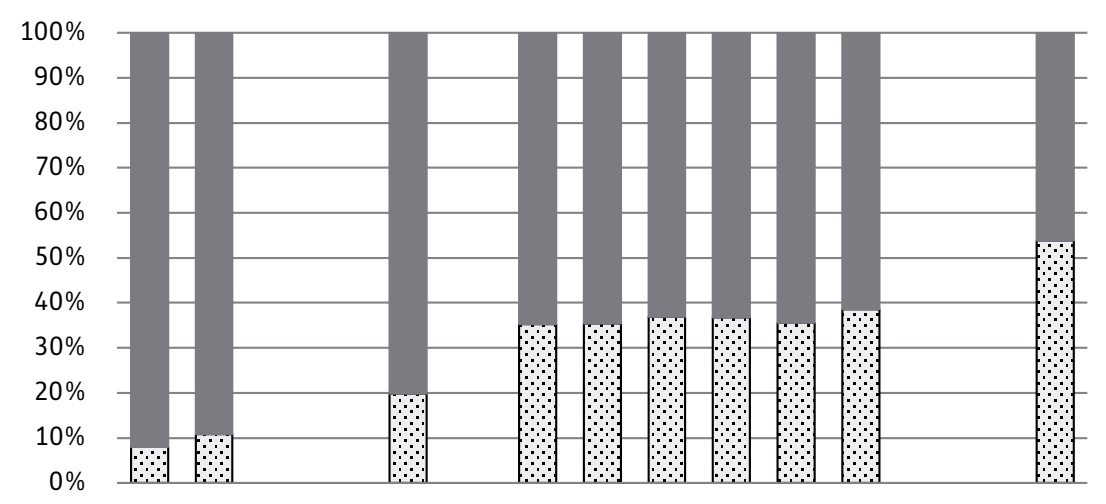

191719201927193019321933194119471953195719621967197319771987

[.7 mujeres hombres

Fuente. Anuario Estadístico de España, Fondo INEbase/Historia. Elaboración propia.

Ahora bien, quedarse solo con esta idea significa tener una visión un tanto incompleta. Durante la segunda fase descrita, las cifras evidencian que no hubo cambios significativos en la redistribución del alumnado según el sexo; pero si uno se fija en la evolución del número de matrículas, se observa que ahí sí hubo más movimiento. En el gráfico 2 se recoge

16 Esta cuestión ha suscitado cierta polémica. Mientras Sanchidrián considera que durante la primera etapa de la dictadura la población femenina en la enseñanza media se estancó tanto en términos absolutos como en términos relativos (Sanchidrián Blanco 1999, 599-600), Canales defiende la postura contraria: a pesar de que el nuevo régimen hacía bandera de la inferioridad intelectual de las mujeres, más mujeres accedieron a institutos y universidades durante el período de posguerra (Canales 2012, 384-385). 
la evolución de las tasas de crecimiento del alumnado según el sexo y con respecto al censo total de población. En esta ocasión, y aplicable a todo el espectro cronológico considerado, el elemento distintivo no fue la invariabilidad sino la progresión gradual sostenida. También entre 1941 y 1957 el número de matrículas aumentó, y ese incremento se dio de forma paralela en ambos sexos.

En la etapa educativa de la enseñanza media, la paridad entre el alumnado no se alcanzó hasta finales de los años setenta. A nivel estatal, Judith Carbajo sitúa como punto de inflexión el curso académico 1977-1978, momento en que las alumnas matriculadas en los estudios de bachillerato representaban un 50,8\% del total, superando en valores relativos y absolutos al alumnado masculino (Carbajo Vázquez 2003, 233). En 1987 se mantuvo la misma dinámica, ellas ya eran la parte mayoritaria entre los estudiantes (un 54\%).

Gráfico 2. Tasas de crecimiento del alumnado matriculado en la Enseñanza Media respecto al censo total de población, DUB 1917-1987

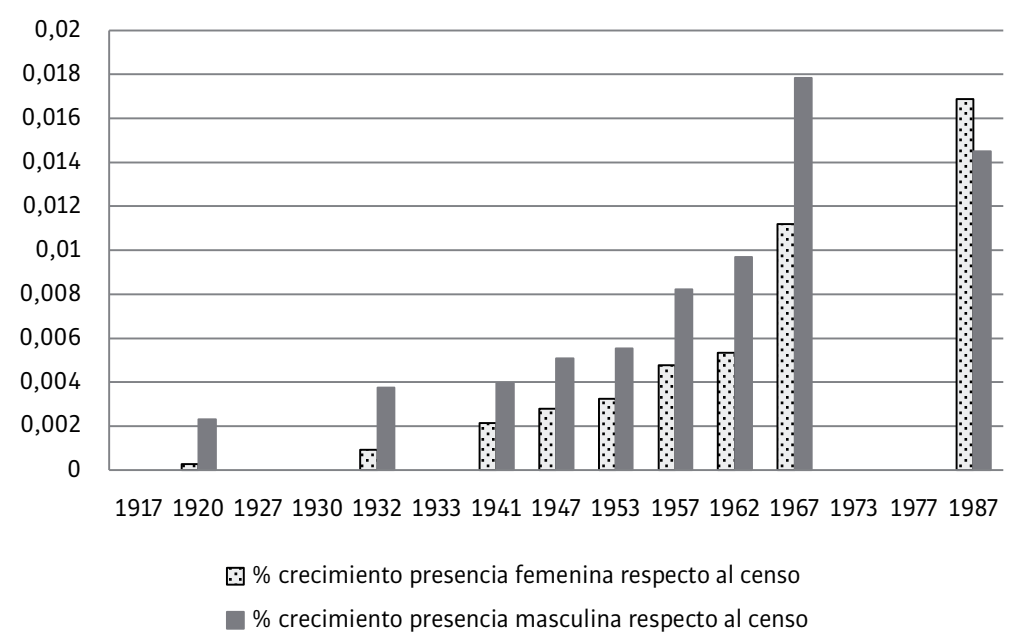

Fuente. Anuario Estadístico de España, Fondo INEbase/Historia. Elaboración propia. 


\section{Educación superior: la enseñanza universitaria}

Sin lugar a duda, a lo largo del siglo xx la gran revolución - en cuanto a presencia femenina se refiere - tuvo lugar en la etapa de educación superior, específicamente en la enseñanza universitaria. Si en el curso 19161917 únicamente 6 de cada 100 alumnos matriculados eran mujeres, en el curso 1986-1987 esta proporción cambió radicalmente: de cada 100 matrículas, 55 eran de mujeres. Esta comparativa ilustra claramente la transformación del panorama universitario a lo largo del siglo. No obstante, el riesgo a la hora de valorar estas cifras es quedarse únicamente con las cifras extremas. En efecto, la entrada de mujeres a la enseñanza universitaria ha sido uno de los grandes logros del siglo xx, pero, en parte, la magnitud del cambio se debe a que se partía prácticamente de la nada. ${ }^{17}$ En el cuadro 1 y en el gráfico 3 se puede reseguir la evolución histórica de la distribución porcentual del alumnado universitario.

\section{Cuadro 1. Porcentaje de alumnas universitarias} respecto al total del alumnado, DUB 1917-1987

$\begin{array}{rrrrrr}1917 & {[\mathrm{r}] 6 \%} & 1933 & 7 \% & 1962 & 26 \% \\ 1920 & {[\mathrm{r}] 7 \%} & 1941 & 10 \% & 1967 & 31 \% \\ 1927 & 14 \% & 1947 & 12 \% & 1973 & 37 \% \\ 1930 & 7 \% & 1953 & 17 \% & 1977 & {[\mathrm{~s}] 43 \%} \\ 1932 & 6 \% & 1957 & 21 \% & 1987 & \text { [t] } 55 \%\end{array}$

Leyenda. [r]: De la UB, se contabilizan como enseñanzas universitarias a «Practicantes» $y$ «Matronas». [s]: Se añaden la UAB, universidad de nueva creación (facultades de Ciencias, Ciencias Económicas, Derecho, Filosofía y Letras, Medicina y Ciencias de la Información). [t]: Se añaden nuevas facultades a la UB (Bellas Artes y Psicología)

y a la UAB (Ciencias Políticas y Sociología y Psicología). Fuente. Anuario Estadístico de España, Fondo INEbase/Historia. Elaboración propia.

17 En España, hasta 1910 las mujeres no pudieron acceder a la universidad sin solicitar un permiso especial previamente: Real orden disponiendo se considere derogada la de 11 de Junio de 1888, y que por los Jefes de los Establecimientos docentes se concedan, sin necesidad de consultar a la Superioridad, las inscripciones de matrícula [...], solicitadas por las mujeres, Boletín Oficial del Estado, núm. 68 (1910): 497 (Flecha García 2011). 
Gráfico 3. Distribución porcentual del alumnado de enseñanza universitaria, DUB 1917-1987

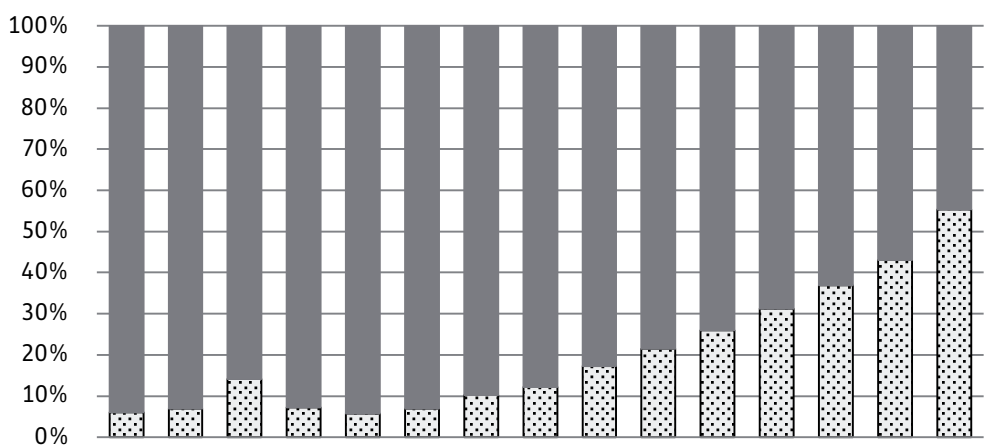

191719201927193019321933194119471953195719621967197319771987

$\checkmark$ mujeres hombres

Fuente. Anuario Estadístico de España, Fondo INEbase/Historia. Elaboración propia.

Para calibrar correctamente esta radical transformación, los datos absolutos y relativos de crecimiento de las matrículas universitarias permiten entrever los matices (gráfico 4). El primer elemento por constatar es que la matrícula femenina y la matrícula masculina tienen dinámicas distintas de origen, pero se interconectan entre sí posteriormente. El rasgo definitorio de la trayectoria de las matrículas femeninas es el de ser un proceso nuevo: consiguen poner un pie dentro y de ahí empiezan a crecer. Por el contrario, el elemento característico de la presencia masculina en la universidad es la continuidad: ellos ya estaban en la institución, luego se adaptaron a los cambios. Ambas trayectorias se complementan a medida que se avanza en la cronología, y la clave está en identificar si el crecimiento total de matrículas fue resultado de un aumento paralelo de ambos sexos o bien si uno de los dos grupos fue preeminente.

Comparando los gráficos 4 y 5 , se observa que, por lo menos, hasta principios de los sesenta, la población universitaria se mantuvo estable: no decrecía, tampoco aumentaba de forma relevante. Quizás se puede apuntar un matiz: comparando las tasas de crecimiento por sexos, las del alumnado femenino son ligeramente superiores a las masculinas. De ahí que la distribución porcentual de hombres y mujeres se fuera modificando lentamente. A partir de la segunda mitad de los sesenta, se inició una nueva 
dinámica: el crecimiento de la población universitaria se aceleró, y este cambio de ritmo se dio tanto en las matrículas masculinas como en las femeninas. Finalmente, a finales de los ochenta se instauró otra dinámica de crecimiento distinta: las mujeres mantuvieron el ritmo alcanzado en la década de los setenta y consiguieron invertir la proporción (ellas eran la parte mayoritaria). Contrariamente, las matrículas masculinas siguieron incrementándose, pero el ritmo de crecimiento se ralentizó.

Gráfico 4. Tasa de crecimiento del alumnado matriculado en la Enseñanza universitaria respecto al censo total de población, DUB 1917-1987

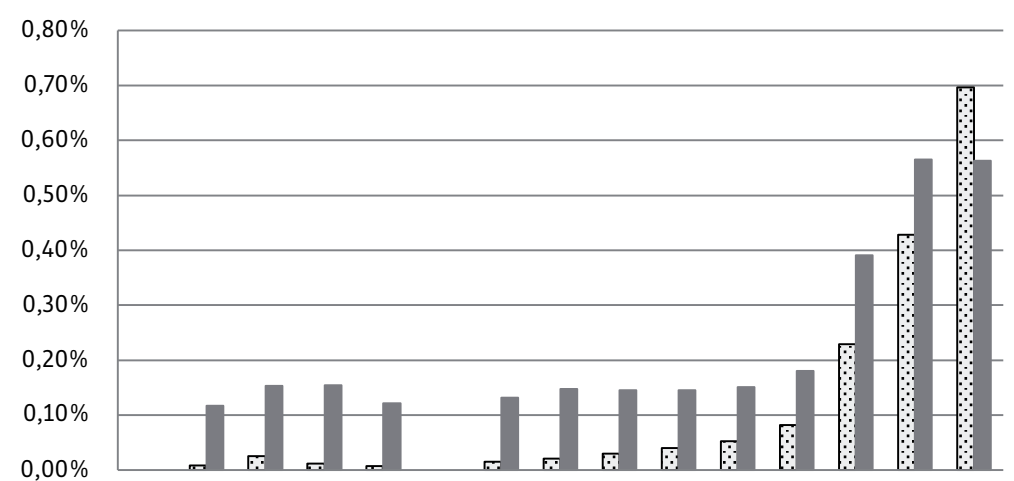

191719201927193019321933194119471953195719621967197319771987

\% crecimiento presencia femenina respecto al censo
$\%$ crecimiento presencia masculina respecto al censo

Fuente. Anuario Estadístico de España, Fondo INEbase/Historia. Elaboración propia. 
Gráfico 5. Total alumnado matriculado

en la Enseñanza universitaria, DUB 1917-1987

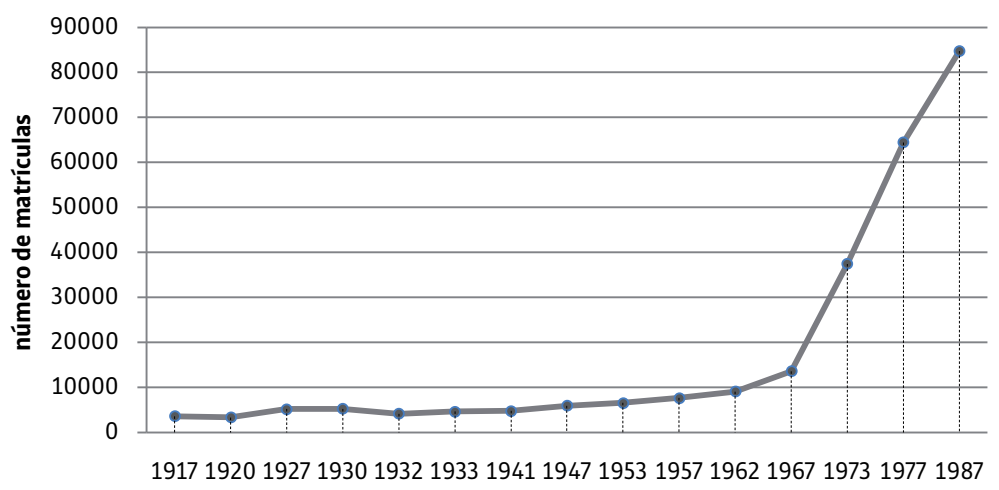

cursos académicos

Fuente. Anuario Estadístico de España, Fondo INEbase/Historia. Elaboración propia.

Entrelazando las características extraídas del análisis de la presencia femenina en la enseñanza media y en la enseñanza universitaria se puede concluir que en ambas etapas educativas la presencia de las mujeres fue aumentando progresivamente: no solo más mujeres estudiaban, sino que ese incremento fue general a todas las etapas educativas. A pesar de que el sistema educativo seleccionaba al alumnado por razón de género (sin olvidar que también por razón de clase), los datos recogidos muestran que este proceso selectivo se fue suavizando - según las épocasa lo largo de todo el período analizado. Especialmente, en lo que a la enseñanza universitaria se refiere.

Durante la etapa franquista, aunque pueda parecer paradójico, ${ }^{18}$ no solo más mujeres accedieron a una mayor formación académica —enseñanza media—, sino que más mujeres consiguieron llegar a la universidad. El

18 Canales Serrano emplea el término "paradoja” para describir la situación existente entre la posición doctrinal antifeminista del nuevo régimen político y la presencia de mujeres en el sistema educativo: «Thus, during the forties there were more girls than ever before taking the bachillerato. A similar evolution is also seen in the number of female university students» (Canales 2012, 384-385). A grandes rasgos, compartimos ampliamente las explicaciones que ofrece para solucionar dicha paradoja, especialmente interesante es la tesis de que «las tendencias de cambio social presentan una capacidad de desarrollo bastante autónoma respecto a las políticas gubernamentales y la ideología oficial» (Canales 2012). 
Nuevo Estado no rompió radicalmente con lo heredado, aunque ese fuera su primer y único objetivo en materia educativa. No podían expulsar por decreto a las mujeres de las aulas universitarias, y en su defecto optaron por indicarles el camino correcto según su condición biológica (esposa y madre), tal y como postulaba la ideología nacional-católica. ${ }^{19}$

\section{9-1957: la Universidad en el primer franquismo}

\section{El alumnado universitario}

Hasta ahora hemos visto la evolución de la población universitaria a lo largo del siglo. Para la primera etapa del régimen franquista ampliaremos el análisis a la distribución del alumnado en las distintas facultades.

\section{Estudiantes y facultades}

Los datos representados en el gráfico 6, que muestran la evolución del número total de matriculados, ponen de manifiesto que este fue creciendo de forma sostenida, pero a un ritmo más bien lento. Más si se compara con la velocidad de crucero que alcanzaría las siguientes décadas. Asimismo, gracias a las líneas de tendencias lineales se puede ver más claramente como el crecimiento de las matrículas femeninas fue ligeramente superior al de las matrículas masculinas. Aunque esa posición levemente preponderante no modificó la dinámica general. Una dinámica cuyo rasgo más característico era su estatismo: ni decrecía, ni experimentaba incrementos bruscos.

19 En ningún momento de los largos cuarenta años de dictadura franquista, no hubo disposición legal alguna que prohibiese o limitara el acceso de las mujeres a la enseñanza superior. Sin embargo, en todas las leyes educativas (y sus posteriores reformas), bien por omisión o explícitamente, se establecía la segregación institucional — fin de la coeducación - y la segregación curricular —Enseñanzas del Hogar y contenidos evaluables - como principios educativos fundamentales. 
Gráfico 6. Enseñanza universitaria.

Totales: alumnado de la UB y tendencias de crecimiento entre los cursos 1939-1940 y 1956-1957

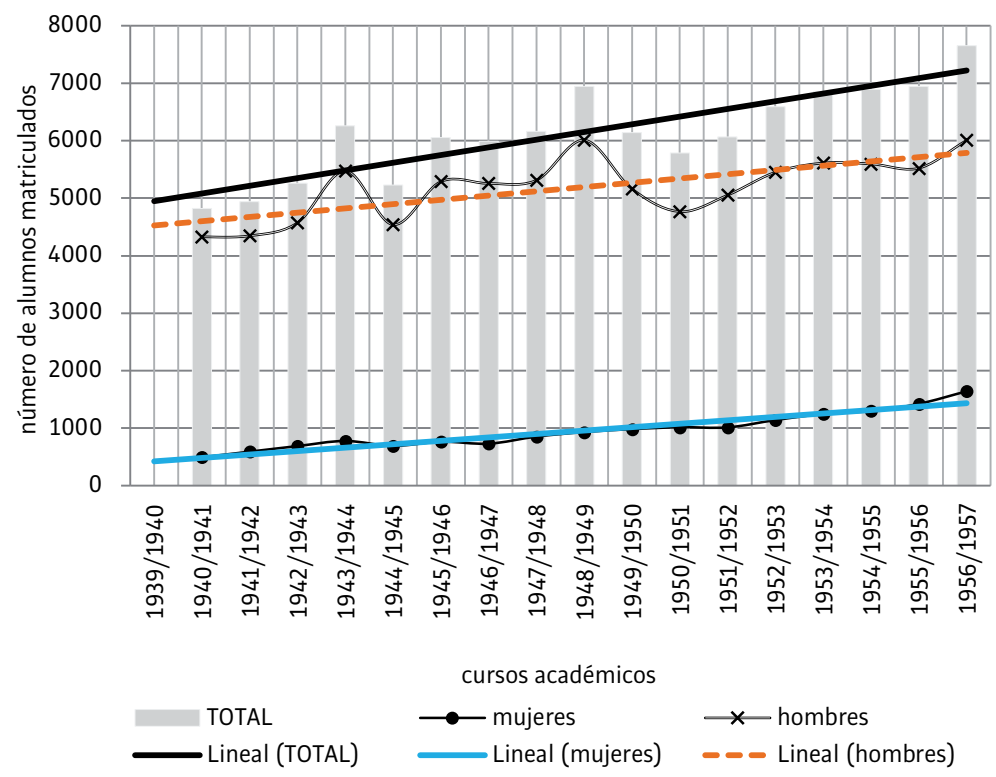

Fuente. Anuario Estadístico de España, Fondo INEbase/Historia. Elaboración propia.

Sin embargo, en el análisis de la distribución del alumnado entre las distintas facultades se pueden identificar dinámicas de comportamiento diferenciadas según sean hombres o mujeres (cuadro 2). El primer elemento destacable es que en términos porcentuales todas las facultades registraron un crecimiento positivo. De media, en el conjunto de las facultades este aumento puede cifrarse en 9 puntos porcentuales. Tomando como dato de referencia este incremento del $9 \%$, se pueden agrupar las facultades en tres grupos: las que crecieron de forma similar o próxima al conjunto de las facultades (Ciencias un 10\% y Farmacia un 14\%); las que quedaron muy por debajo de la media (Derecho y Medicina, que aumentaron solo un $4 \%$ respecto al inicio del período); y, finalmente, Filosofía y Letras, que creció cuatro veces más que la media (un 39\%). 
Cuadro 2. Distribución numérica y porcentual de mujeres y hombres en las distintas facultades de la UB (cursos 1941-1942, 1946-1947, 1950-1951 y 1956-1957)

\begin{tabular}{|c|c|c|c|c|c|c|c|c|c|}
\hline & \multicolumn{8}{|c|}{ Cursos académicos } & \multirow{3}{*}{$\begin{array}{c}\text { Aumento } \\
\text { porcentual } \\
\text { del número de } \\
\text { mujeres por } \\
\text { facultades entre } \\
1941 / 1942- \\
1956 / 1957\end{array}$} \\
\hline & \multicolumn{2}{|c|}{$1941 / 1942$} & \multicolumn{2}{|c|}{$1946 / 1947$} & \multicolumn{2}{|c|}{$1950 / 1951$} & \multicolumn{2}{|c|}{$1956 / 1957$} & \\
\hline & 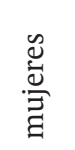 & 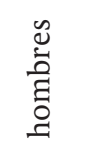 & & 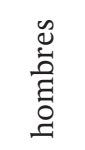 & 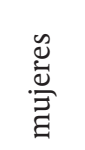 & 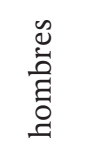 & $\frac{\mathscr{U}}{\stackrel{\Xi}{\Xi}}$ & 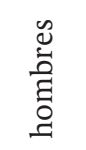 & \\
\hline \multirow{2}{*}{ Ciencias } & 156 & 1082 & 154 & 1430 & 149 & 860 & 315 & 1058 & \\
\hline & $13 \%$ & $87 \%$ & $10 \%$ & $90 \%$ & $15 \%$ & $85 \%$ & $23 \%$ & $77 \%$ & $10 \%$ \\
\hline \multirow{2}{*}{ C. Pol. Eco. } & - & - & - & - & - & - & 17 & 529 & \\
\hline & & & & & & & $3 \%$ & $97 \%$ & $3 \%$ \\
\hline \multirow{2}{*}{ Derecho } & 25 & 1148 & 23 & 1572 & 47 & 1578 & 110 & 1817 & \\
\hline & $2 \%$ & $98 \%$ & $1 \%$ & $99 \%$ & $3 \%$ & $97 \%$ & $6 \%$ & $94 \%$ & $4 \%$ \\
\hline \multirow{2}{*}{ Farmacia } & 222 & 474 & 289 & 437 & 378 & 504 & 582 & 696 & \\
\hline & $32 \%$ & $68 \%$ & $40 \%$ & $60 \%$ & $43 \%$ & $57 \%$ & $46 \%$ & $54 \%$ & $14 \%$ \\
\hline \multirow{2}{*}{$\begin{array}{l}\text { Filosofía y } \\
\text { Letras }\end{array}$} & 169 & 538 & 234 & 239 & 368 & 174 & 520 & 313 & \\
\hline & $24 \%$ & $76 \%$ & $49 \%$ & $51 \%$ & $68 \%$ & $32 \%$ & $62 \%$ & $38 \%$ & $39 \%$ \\
\hline \multirow{2}{*}{ Medicina } & 19 & 1103 & 30 & 1578 & 74 & 1650 & 97 & 1594 & \\
\hline & $2 \%$ & $98 \%$ & $2 \%$ & $98 \%$ & $4 \%$ & $96 \%$ & $6 \%$ & $94 \%$ & $4 \%$ \\
\hline \multirow{2}{*}{ TOTALES } & 591 & 4345 & 730 & 5256 & 1016 & 4766 & 1641 & 6007 & \\
\hline & $12 \%$ & $88 \%$ & $12 \%$ & $88 \%$ & $18 \%$ & $82 \%$ & $21 \%$ & $79 \%$ & $9 \%$ \\
\hline
\end{tabular}

Fuente. Anuario Estadístico de España, Fondo INEbase/Historia. Elaboración propia.

Esta clasificación sintetiza los rasgos definitorios de la presencia femenina en la universidad durante la primera etapa de la dictadura franquista: la facultad — considerada — más apropiada para las mujeres era Filosofía y 
Letras. ${ }^{20} \mathrm{Si}$ se optaba por un itinerario de ciencias, Farmacia era la más común. ${ }^{21}$ Ciencias era menos frecuente, pero posible o deseable. En cambio, las tres facultades restantes eran cotos completamente masculinizados. ${ }^{22}$

A lo largo de estas dos décadas se instauró y se mantuvo prácticamente intacta la distribución femenina entre las distintas facultades universitarias. En los primeros años del nuevo régimen político ellas representaban solo un 12\% del total del alumnado universitario; en el curso 1956-1957 seguían siendo una minoría (no llegaban ni a una cuarta parte del total, un 21\%).

\section{Enseñanza post-universitaria, doctorados}

Por último, en cuanto al alumnado, no ha sido posible reconstruir datos sobre los estudios post-universitarios: el doctorado (matrícula en los cursos de doctorado o número de tesis leídas). ${ }^{23}$ El motivo por el cual no existen datos sobre tesis leídas en la Universidad de Barcelona se explica porque hasta 1953 la Universidad de Barcelona no tenía el derecho de otorgar títulos de doctor: era requisito indispensable ir a Madrid. ${ }^{24}$ De ahí, que los pocos datos sobre tesis leídas hasta ese curso siempre se vinculasen al centro madrileño. No obstante, debería haber por lo menos datos sobre el alumnado en los cursos de doctorado, pues desde 1943 estos se podían impartir en todas las universidades. ${ }^{25}$ Pese a todo, de la Universi-

20 Filosofía y Letras no era la primera preferencia de estudio entre las alumnas que iban a la universidad, pero sí era la facultad donde la presencia femenina era mayor.

21 Farmacia fue durante el primer franquismo la facultad de preferencia de las universitarias a la hora de elegir qué carrera estudiar.

22 Orientar debidamente a las muchachas implicaba delimitar qué profesiones eran netamente femeninas y cuáles no. Las guías de profesiones femeninas servían a tal propósito, un ejemplo: Bohigas Gavilanes (1947). Para un estudio detallado sobre estos materiales, véase Sanchidrián Blanco (2008, 236-245).

23 No existen, o no tenemos constancia, de estudios que traten sobre los alumnos de doctorado o que analicen la producción de tesis doctorales durante la etapa franquista. Tan solo tenemos conocimiento de la investigación llevada a cabo por María Jesús Matilla sobre la presencia de las mujeres en los estudios de doctorado entre 1882 y 1954 (Matilla Quiza 2015).

24 Decreto de 25 de junio de 1954 por el que se regula el procedimiento para conferir el grado de Doctor en todas las Universidades, Boletín Oficial del Estado, núm. 193 (1954): 4724-4725. En 1953 la Universidad de Barcelona, junto con la Universidad de Salamanca, conseguía dicha prerrogativa. Un año más tarde se haría extensible al resto de centros.

25 Ley de 29 de julio de 1943 sobre ordenación de la Universidad española, Boletín Oficial del Estado, núm. 212 (31 jul. 1943): 7406-7431. 
dad de Barcelona se han localizado datos relativos al doctorado del curso 1957-1958, que ofrecen una foto fija de la presencia de las mujeres en los estudios de máximo rango (cuadro 3, columna A).

Comparando los datos de matrícula de los cursos de doctorado (cuadro 3, columna A) con las matrículas de licenciatura (cuadro 4), se observa que en casi todas las facultades los porcentajes de mujeres matriculadas respecto a los hombres eran menores: por ejemplo, en Derecho, durante la licenciatura, la proporción alumnas-alumnos era 6\%-94\%, en los cursos de doctorado era 4\%-96\%. Los cambios producidos en las distribuciones porcentuales fueron más evidentes en algunas facultades que en otras. Por ejemplo, en Farmacia las matrículas de licenciatura femeninas eran casi la mitad de los estudiantes ( $44 \%$ ), pero en los cursos de doctorado tan solo representaban una cuarta parte del total (24\%). Ciencias es la única facultad donde el porcentaje de mujeres matriculadas en el doctorado fue superior que el registrado en la matrícula de licenciatura. Esta situación, sin embargo, parece circunstancial del año analizado.

En líneas generales, las cifras ponen de manifiesto que en los estudios universitarios de mayor rango las probabilidades de cursar u obtener un doctorado también eran diferentes según se fuera hombre o mujer.

Cuadro 3. Alumnado matriculado y tesis de doctor aprobadas en el curso 1957-1958 en la UB. Datos numéricos y porcentuales

Columna A

\begin{tabular}{cccc} 
& \multicolumn{3}{c}{$\begin{array}{c}\text { Alumnado matriculado } \\
\text { en el doctorado }\end{array}$} \\
\cline { 2 - 4 } & $M$ & $H$ & $T$ \\
\hline \multirow{3}{*}{ Ciencias } & 14 & 53 & 67 \\
\cline { 2 - 4 } & $21 \%$ & $79 \%$ & \\
\hline
\end{tabular}

C. Pol. Eco.

\begin{tabular}{cccc} 
& - & - & \\
\hline \multirow{2}{*}{ Derecho } & 3 & 68 & 71 \\
\cline { 2 - 4 } & $4 \%$ & $96 \%$ & \\
\hline
\end{tabular}

Columna B

Tesis de doctor aprobadas

\begin{tabular}{cccc} 
& $M$ & $H$ & $T$ \\
\cline { 2 - 3 } $\mathrm{N}^{\circ}$ & 1 & 2 & 3 \\
\cline { 2 - 3 }$\%$ & $33 \%$ & $67 \%$ & \\
\cline { 2 - 3 }
\end{tabular}

\begin{tabular}{cccc}
$\mathrm{N}^{\mathrm{o}}$ & \multicolumn{1}{c}{-} & - & \\
\cline { 2 - 3 }$\%$ & - & - & \\
\cline { 2 - 3 } $\mathrm{N}^{\mathrm{o}}$ & 0 & 3 & 3 \\
\cline { 2 - 4 }$\%$ & $0 \%$ & $100 \%$ & \\
\cline { 2 - 3 }
\end{tabular}




\begin{tabular}{|c|c|c|c|c|c|c|c|}
\hline & \multicolumn{3}{|c|}{ Columna A } & & \multicolumn{3}{|c|}{ Columna B } \\
\hline & \multicolumn{3}{|c|}{$\begin{array}{c}\text { Alumnado matriculado } \\
\text { en el doctorado }\end{array}$} & & \multicolumn{3}{|c|}{ Tesis de doctor aprobadas } \\
\hline & $M$ & $H$ & $T$ & & $M$ & $H$ & $T$ \\
\hline \multirow{2}{*}{ Farmacia } & 12 & 37 & 49 & $\mathrm{~N}^{\mathrm{o}}$ & 0 & 3 & 3 \\
\hline & $24 \%$ & $76 \%$ & & $\%$ & $0 \%$ & $100 \%$ & \\
\hline \multirow{2}{*}{$\begin{array}{l}\text { Filosofía y } \\
\text { Letras }\end{array}$} & 26 & 26 & 52 & $\mathrm{~N}^{\mathrm{o}}$ & $\mathrm{s} / \mathrm{d}$ & $\mathrm{s} / \mathrm{d}$ & 0 \\
\hline & $50 \%$ & $50 \%$ & & $\%$ & - & - & \\
\hline \multirow{2}{*}{ Medicina } & 3 & 92 & 95 & $\mathrm{~N}^{\mathrm{o}}$ & 2 & 22 & 24 \\
\hline & $3 \%$ & $97 \%$ & & $\%$ & $8 \%$ & $92 \%$ & \\
\hline \multirow{2}{*}{ TOTALES } & 58 & 276 & 334 & $\mathrm{~N}^{\mathrm{o}}$ & 3 & 30 & 33 \\
\hline & $17 \%$ & $83 \%$ & & $\%$ & $9 \%$ & $91 \%$ & \\
\hline
\end{tabular}

Leyenda. M: Mujeres, $\mathrm{H}$ : Hombres, T: Totales

Fuente. Instituto Nacional de Estadística, Presidencia del Gobierno, Estadística de la enseñanza superior en España. Curso 1957-1958 (Madrid: Instituto Nacional de Estadística, 1960), 126.

Datos porcentuales de elaboración propia.

Cuadro 4. Alumnado matriculado en las distintas facultades en el curso 1957-1958 en la UB. Datos numéricos y porcentuales

\begin{tabular}{lcccc} 
& & $M$ & $H$ & $T$ \\
\hline \multirow{2}{*}{ Ciencias } & $\mathrm{N}^{\mathrm{O}}$ & 331 & 1370 & 1701 \\
\cline { 2 - 5 } & $\%$ & $19 \%$ & $81 \%$ & \\
\hline \multirow{2}{*}{ C. Pol. Eco. } & $\mathrm{N}^{\mathrm{o}}$ & 28 & 687 & 715 \\
\cline { 2 - 5 } Derecho & $\%$ & $4 \%$ & $96 \%$ & \\
\hline \multirow{2}{*}{ Farmacia } & $\mathrm{N}^{\mathrm{o}}$ & 114 & 1754 & 1868 \\
\cline { 2 - 5 } & $\%$ & $6 \%$ & $94 \%$ & \\
\hline
\end{tabular}




\begin{tabular}{lcccc} 
& & $M$ & $H$ & $T$ \\
\hline \multirow{2}{*}{ Filosofía y Letras } & $\mathrm{N}^{\circ}$ & 589 & 381 & 970 \\
\cline { 2 - 5 } & $\%$ & $61 \%$ & $39 \%$ & \\
\hline \multirow{2}{*}{ Medicina } & $\mathrm{N}^{\circ}$ & 117 & 1935 & 2052 \\
\cline { 2 - 5 } & $\%$ & $6 \%$ & $94 \%$ & \\
\hline \multirow{2}{*}{ TOTALES } & $\mathrm{N}^{\circ}$ & 1806 & 6925 & 8731 \\
\cline { 2 - 5 } & $\%$ & $21 \%$ & $79 \%$ & \\
\hline
\end{tabular}

Leyenda. M: Mujeres, $\mathrm{H}$ : Hombres, T: Totales

Fuente. Anuario Estadístico de España, Fondo INEbase/Historia. Elaboración propia.

\section{El profesorado 26}

En la parte introductoria de este artículo se ha mencionado brevemente la cuestión de las fuentes empleadas para la reconstrucción estadística de la población universitaria. En el caso del profesorado es preciso retomar el tema brevemente, pues las interpretaciones que se presentarán a continuación deben tomarse con precaución.

En los anuarios estadísticos, los datos relativos al profesorado eran muy pobres: eran datos totales y sin distinguir el sexo ni la categoría profesional. La obra Estadística de la Enseñanza en España resolvió estos déficits informativos con creces. Sin embargo, las cifras proporcionadas tenían un pequeño hándicap: para el contexto histórico que documentaban, parecían irreales (plantillas docentes abultadas). Las dudas sobre la fiabilidad de las fuentes requería encontrar un modo de validar dichos datos. La solución fue comparar esos datos (Presidencia del Gobierno 1958) con el listado nominal de profesores de la Memoria de la Universidad de Barcelona de $1956^{27}$ (cuadro 5). En la lista, los profesores estaban clasificados

26 La cuestión de las profesoras universitarias como objeto de estudio histórico es un campo aún por explorar y explotar. Desde la perspectiva histórica, los primeros trabajos al respecto son Flecha García (2010, 2015a), y Rodríguez López (2013). Desde el campo de la sociología son indispensables las aportaciones metodológicas e interpretativas de García de Cortázar Nebreda y García de León (1997), García de León y García de Cortázar Nebreda (2001), García de León (2002).

27 (Universitat de Barcelona 1950, 1956). Los anuarios y memorias anuales de la UB son sistemáticos y seriados a partir de la segunda mitad de los años sesenta. Para la cronología del primer franquismo solo existen dos volúmenes: uno de 1950 y uno de 1956. 
por facultades y según el rango académico que ostentaban. Comparando números y porcentajes, se confirmaban las sospechas iniciales: los datos que proporcionaba el INE estaban sobredimensionados.

Cuadro 5. Comparativa del curso académico 1955-1956: datos de la Estadística de la Enseñanza Universitaria (b) y de la Memoria de la Universidad de Barcelona (c). Totales numéricos y porcentuales

\begin{tabular}{|c|c|c|c|c|}
\hline & \multicolumn{2}{|c|}{ Estadísticas INE (b) } & \multicolumn{2}{|c|}{ Memoria UB (c) } \\
\hline & $M$ & $H$ & $M$ & $H$ \\
\hline \multirow{2}{*}{ Ciencias } & 11 & 113 & 0 & 49 \\
\hline & $9 \%$ & $91 \%$ & $0 \%$ & $100 \%$ \\
\hline \multirow{2}{*}{ C. Políticas y Económicas } & 1 & 48 & 0 & 12 \\
\hline & $2 \%$ & $98 \%$ & $0 \%$ & $100 \%$ \\
\hline \multirow{2}{*}{ Derecho } & 2 & 99 & 0 & 31 \\
\hline & $2 \%$ & $98 \%$ & $0 \%$ & $100 \%$ \\
\hline \multirow{2}{*}{ Farmacia } & 3 & 29 & 2 & 22 \\
\hline & $9 \%$ & $91 \%$ & $8 \%$ & $92 \%$ \\
\hline \multirow{2}{*}{ Filosofía y Letras } & 42 & 114 & 5 & 61 \\
\hline & $27 \%$ & $73 \%$ & $8 \%$ & $92 \%$ \\
\hline \multirow{2}{*}{ Medicina } & 1 & 85 & 0 & 42 \\
\hline & $1 \%$ & $99 \%$ & $0 \%$ & $100 \%$ \\
\hline \multirow{2}{*}{ Todas las facultades } & 60 & 488 & 7 & 217 \\
\hline & $11 \%$ & $89 \%$ & $3 \%$ & $97 \%$ \\
\hline
\end{tabular}

Leyenda. M: Mujeres, $\mathrm{H}$ : Hombres

Fuente. Estadística de la Enseñanza en España, INE (b) y Memorias de la Universidad de Barcelona (c). Elaboración propia. 
Una primera hipótesis de trabajo que podía explicar dicho desfase numérico era que los autores de ambas publicaciones no compartían la misma definición de "personal docente". Así que era necesario fijarse en las categorías docentes que se contabilizaban en una y otra publicación. Para el caso de la Estadística del INE, las categorías docentes contempladas eran: catedráticos, adjuntos, ayudantes, auxiliares, especiales y otros. Un total de seis categorías distintas. En la memoria de la UB solo se utilizaban tres: catedráticos, ayudantes y auxiliares. Además, durante el vaciado documental, se excluyó del recuento final a los docentes listados bajo el epígrafe «De enseñanzas complementarias». En esta lista se encontraban los profesores de Educación Física, Formación Religiosa y Formación Política. ¿Fue esta exclusión la que podía explicar el desfase entre las fuentes? Definitivamente no. La no-concordancia de datos no se debe a la inclusión o no de estos profesores, pues, aun contemplando esta posibilidad, los números siguen sin coincidir. En la edición de 1952 de la colección Estadísticas, los autores advertían que dentro de la categoría genérica de "Profesores especiales" se incluía a los "profesores de Educación Física, Formación Religiosa y Formación Política”. Teniendo en cuenta esto, se procedió a incluirlos en el recuento de la memoria de la UB: los profesores de Religión eran 6 (todos hombres); los profesores de Formación Política eran 11, y en Educación Física había 12 profesores, de los cuales solo 3 eran mujeres. Si se hace el simple ejercicio de sumar estas cifras a los datos totales de la columna de la derecha, los números no salen. Por todo lo dicho, los datos que se exponen a continuación deben tomarse con cautela. Si bien en cifras absolutas la fiabilidad es más que cuestionable, la evolución del conjunto del estamento en términos relativos y porcentuales puede interpretarse como orientativa.

Pasando a la parte interpretativa, se observa que, durante la primera etapa del régimen franquista, la presencia de mujeres en el estamento docente fue una cuestión puntual y aislada (Montoro Romero 1981, 76-77). En el cuadro 6 se puede reseguir la evolución porcentual de la proporción del profesorado según el sexo entre 1946-1947 y 1957-1958. ${ }^{28}$ En el primer 
curso documentado las profesoras eran tan solo un 6\% del total, proporción que al final del período analizado no representaba más del $10 \%$.

\section{Cuadro 6. Detalle porcentual según el sexo del cuerpo docente} universitario, UB cursos de 1939-1940 a 1957-1958

\begin{tabular}{lll} 
& $M$ & $H$ \\
\hline $1939-1940(\mathrm{a})$ & - & - \\
\hline $1940-1941$ (a) & - & - \\
\hline $1941-1942(\mathrm{a})$ & - & - \\
\hline $1942-1943$ (a) & - & - \\
\hline $1943-1944$ (a) & - & - \\
\hline $1944-1945$ (a) & - & - \\
\hline $1945-1946$ (a) & - & - \\
\hline $1946-1947$ (a) & $6 \%$ & $94 \%$ \\
\hline $1947-1948$ (b) & $11 \%$ & $89 \%$ \\
\hline $1948-1949$ (b) & $6 \%$ & $94 \%$ \\
\hline
\end{tabular}

\begin{tabular}{ccc} 
& $M$ & $H$ \\
\hline $1949-1950(\mathrm{~b})$ & $4 \%$ & $96 \%$ \\
\hline $1950-1951$ (b) & $9 \%$ & $91 \%$ \\
\hline $1951-1952$ (b) & $9 \%$ & $91 \%$ \\
\hline $1952-1953(\mathrm{~b})$ & $8 \%$ & $92 \%$ \\
\hline $1953-1954(\mathrm{~b})$ & $9 \%$ & $91 \%$ \\
\hline $1954-1955(\mathrm{a})$ & - & - \\
\hline $1955-1956$ (b) & $11 \%$ & $89 \%$ \\
\hline $1956-1957$ (b) & $8 \%$ & $92 \%$ \\
\hline $1957-1958$ (b) & $10 \%$ & $90 \%$ \\
\hline
\end{tabular}

Nota. Para todos los cursos, sumatorio de catedráticos, adjuntos, encargados de curso, ayudantes, auxiliares, especiales y otros. En el curso 1949-1950 no se incluyeron excepcionalmente a los adjuntos en el cómputo final.

Leyenda. M: Mujeres, $\mathrm{H}$ : Hombres

Fuente. Anuario Estadístico de España, Fondo INEbase/Historia (a) y Estadística de la Enseñanza en España, INE (b). Elaboración propia.

El carácter puntual que define a las profesoras universitarias en este período se acentúa si se contabiliza y se compara su presencia en cada una de las facultades. Ahí, la presencia femenina puede ser descrita como excepcional o muy excepcional (gráfico 7). En el curso 1956-1957, de un total de 70 profesoras contabilizadas, 34 eran de la facultad de Filosofía y Letras, 22 de Ciencias, 8 de Farmacia, 4 de Medicina y 2 de Derecho. Para completar la descripción, hay que añadir que profesionalmente estas mujeres se concentraban en la parte baja del escalafón académico: sobre todo había ayudantes y alguna que otra adjunta o encargada de curso. 
Este panorama descrito adquiere mayor relevancia ${ }^{29}$ si se compara con los profesores y su distribución entre las distintas facultades y la categoría profesional ocupada (gráfico 8). Como decíamos al inicio, los hombres eran parte y estaban dentro de la institución universitaria, así que su reparto entre las distintas facultades dependía en gran medida de las dinámicas internas de crecimiento de cada una de las disciplinas científicas. En cuanto a su distribución entre las categorías docentes, esta evolucionaba según la dinámica general marcada por las legislaciones universitarias vigentes. ${ }^{30}$ Cada vez que se creaba una figura académica nueva, la ocupaban.

\section{Gráfico 7. Mujeres docentes. Distribución numérica según la categoría profesional. UB curso 1956-1957}

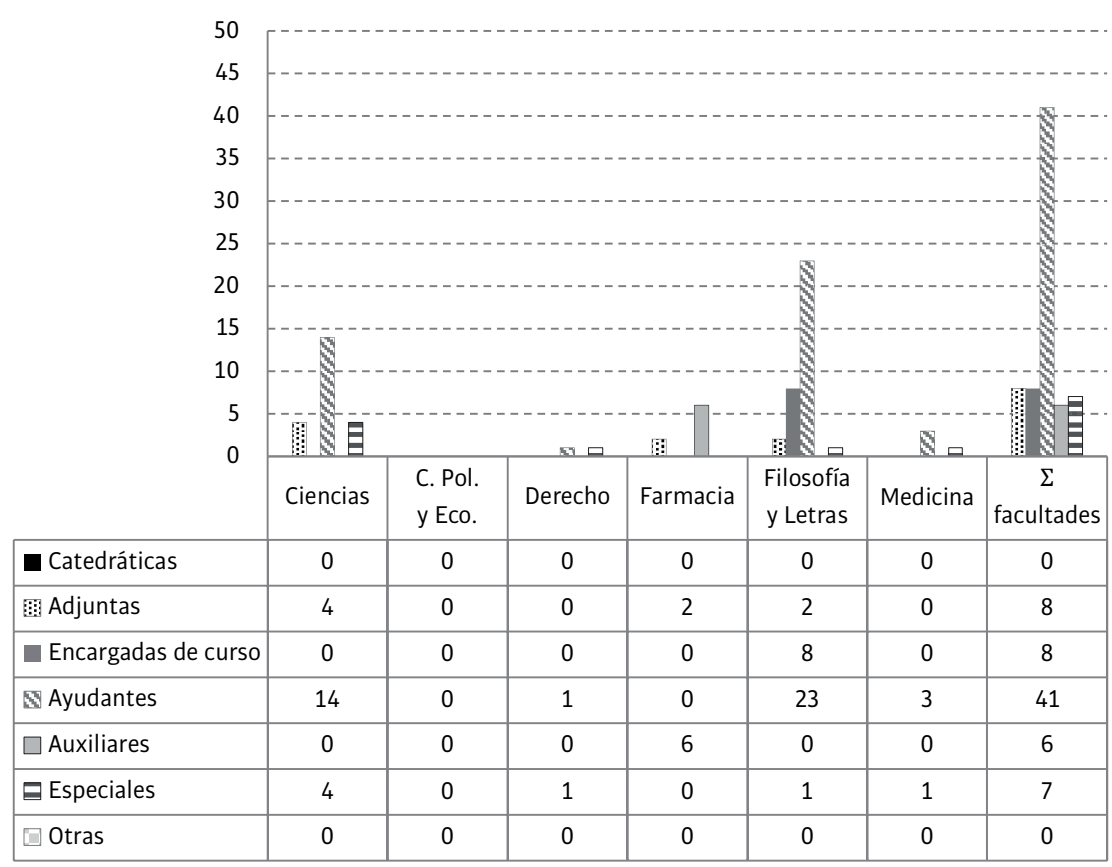

Fuente. Anuario Estadístico de España, Fondo INEbase/Historia (a) y Estadística de la Enseñanza en España, INE (b). Elaboración propia.

29 El eje vertical del gráfico 8 (hombres) es 10 veces mayor que el eje del gráfico 7 (mujeres). 30 Sobre los cambios en el escalafón académico véase Martín Zúñiga (1998). 
Gráfico 8. Hombres docentes. Distribución numérica según la categoría profesional. UB curso 1956-1957

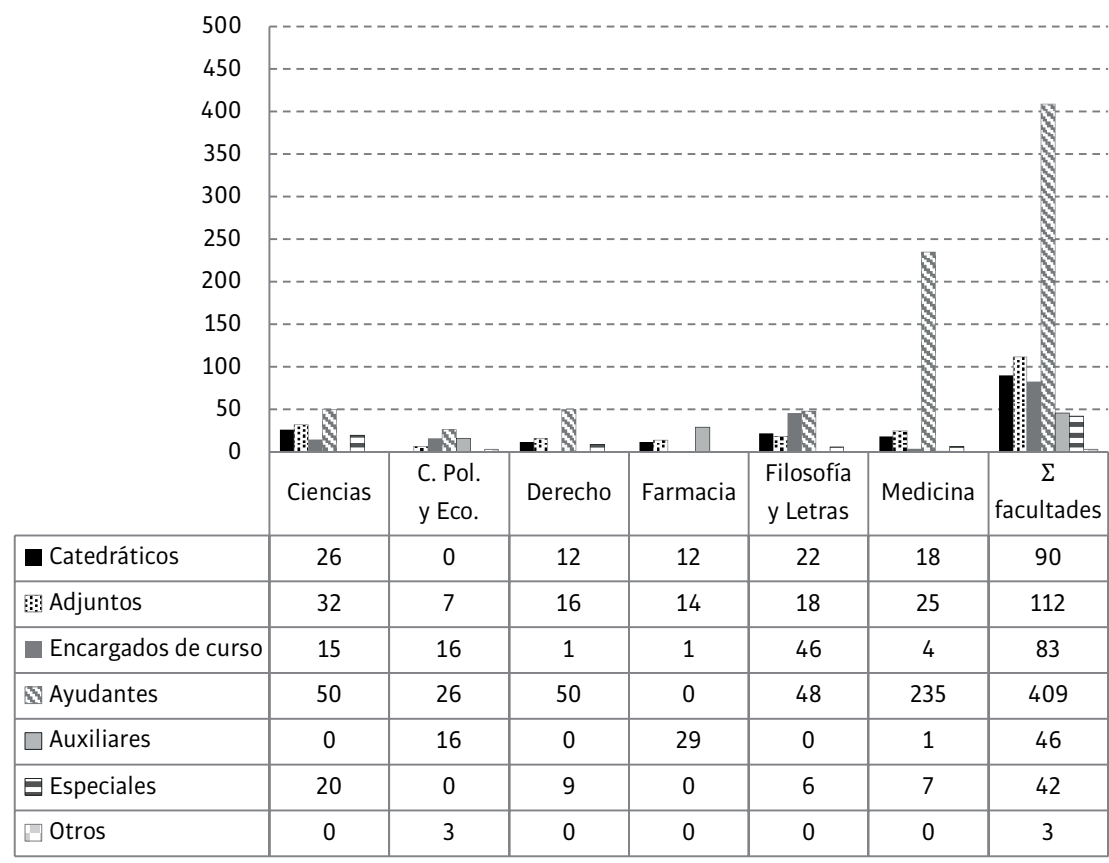

Fuente. Anuario Estadístico de España, Fondo INEbase/Historia (a) y Estadística de la Enseñanza en España, INE (b). Elaboración propia.

Durante el primer franquismo, en líneas generales, la mitad del profesorado masculino se repartía de forma similar entre las tres primeras categorías: los catedráticos eran alrededor de un 11\%, los adjuntos un 14\% y los encargados de curso un $11 \%$. La otra mitad se concentraba, mayoritariamente, en la categoría de los ayudantes y en las otras restantes. Sin embargo, es posible que los porcentajes de las tres primeras categorías fuesen, en realidad, más elevados. La cantidad sobredimensionada de ayudantes (sobre todo en la facultad de Medicina) creemos que altera los porcentajes de reparto entre los distintos rangos del escalafón docente. De hecho, la indefinición de las atribuciones reales del profesor ayudante (no es seguro que todos los ayudantes recibieran compensación económica salarial por sus servicios) refuerza la idea inicial de ser precavidos con las interpretaciones. 


\section{Dinámicas de género y universidad franquista}

Una vez hecho el análisis micro - primer franquismo - y macro — siglo $\mathrm{xx}$ - sobre la presencia de las mujeres en la enseñanza superior, es preciso retomar y dar respuesta a la pregunta planteada al inicio del artículo: ¿Qué papel jugó la instauración del régimen político franquista para con las dinámicas de crecimiento y de redistribución de la población universitaria española? ¿Su postura teórica de alejar a las mujeres de la universidad se tradujo en la práctica? Primero se hará referencia al colectivo estudiantil, luego al estamento docente.

La premisa de partida al hablar del alumnado universitario es que, una vez finalizada la Guerra Civil, el régimen franquista asumió como un hecho consumado que las mujeres estuvieran en la universidad. Que aceptara esta circunstancia no implicaba que fuera de su agrado (ni que lo promoviera), simplemente consideró que con la derogación de las leyes educativas republicanas ${ }^{31} \mathrm{y}$ la promulgación de las nuevas leyes educativas franquistas, ${ }^{32}$ el correcto encauzamiento de la juventud española sería cuestión de tiempo. ${ }^{33}$ Y es que, en realidad, una cosa era tolerar que hubiera universitarias, y otra muy distinta es que estas fuesen consideradas como iguales respecto a sus compañeros universitarios. ${ }^{34}$ Así pues, la

$31 \mathrm{Al}$ poco de iniciarse la guerra, una de las primeras medidas en materia educativa fue derogar el sistema de coeducación de escuelas e institutos: Orden de 4 de septiembre de 1936, dictando reglas a las que habrá de sujetarse la enseñanza en los Institutos nacionales durante el próximo curso escolar, Boletín Oficial del Estado, número 18 (8 sep. 1936): 70-71; Orden de 22 de septiembre de 1936, dictando reglas aclaratorias para la aplicación de las Órdenes de 4 y 5 del actual sobre tareas escolares y coeducación en Escuelas Normales de Comercio y de Trabajo, Boletín Oficial del Estado, núm. 28 (25 set. 1936): 112.

32 La política educativa franquista para con las mujeres se centró en crear un itinerario formativo que las guiara hacia su destino "natural": el hogar y la familia. Las regulaciones no hablaban de prohibiciones, simplemente se marcaban el camino a seguir: estricta separación de los sexos en las aulas y creación de currículums diferenciados para ellas (enseñanzas del hogar). De hecho, la ley de reforma del nuevo bachillerato omite explícitamente a las estudiantes. Es una ley para y por la población masculina: Ley sobre reforma de la Enseñanza Media, Boletín Oficial del Estado, núm. 85 (1938): 1385-1395.

33 Remitimos a las palabras de Pemartín Sanjuán citadas más arriba: «apartándolas de la pedantería feminista de bachilleras y universitarias» $(1937,142)$.

34 En algunos sectores afines al régimen en la década de los cincuenta se debatió - dentro de las filas del régimen — sobre la cuestión de la situación legal y jurídica de la mujer española. Aunque 
aportación genuina del régimen franquista para con las mujeres fue crear un potentísimo aparato legal que (re)orientase debidamente a la población femenina hacia sus verdaderas funciones sociales: ser buenas madres y esposas, recluidas a la esfera familiar. ${ }^{35}$ Este marco legal, ${ }^{36}$ además, se complementó con la promoción de un entorno sociocultural potente e influyente que impregnase completamente la vida privada y pública de las futuras universitarias. ${ }^{37}$

Desde este punto de vista, el régimen franquista sí triunfó en su cometido, pues así lo demuestran los datos sobre las preferencias de estudio de las mujeres en la elección de qué carrera cursar (gráfico 9). $\cdot^{38}$ En el gráfico se recogen datos de ocho cursos académicos entre 1917 y $1987^{39} \mathrm{y}$, para cada año, se reproduce con barras el reparto de las alumnas matriculadas entre las distintas facultades. Así, por ejemplo, en el curso 1956-1957 de cada 100 mujeres que se matriculaban en la universidad, 19 escogían Ciencias, 1 Económicas, 7 elegían Derecho, 35 Farmacia, 32 Filosofía y Letras y 6 Medicina. Una vez descrito el funcionamiento del gráfico, veamos qué tendencias muestra.

Para empezar, a primera vista se puede comprobar que a lo largo del siglo la opción preferente de estudio - la primera, la más escogida — entre

se quiso matizar un poco el discurso, la esencia del modelo de mujer nacional-católico permaneció intacta (Castán Tobeñas 1955).

35 (Gallego Méndez 1983, Molinero 1998, Roca i Girona 2003, Di Febo 2006).

36 (Alted Virgil 1986, Ruiz Franco 2007, Flecha García 2015b).

37 El régimen franquista no inventó de la nada el modelo ideal de mujer como ángel del hogar que se propuso implantar. En esta empresa social de reorganizar toda la sociedad, el régimen estuvo fuertemente influenciado por las visiones decimonónicas sobre la idea de familia y las funciones que sus miembros debían desempeñar en ella. La novedad fue que el franquismo puso toda la maquinaria del estado a conseguir en la teoría y en la práctica la homogenización de la población femenina. Y en ese cometido contó, además, con la inestimable ayuda de la Iglesia Católica. Donde no llegaba la política, llegaba la religión. Los discursos de Pilar Primo de Rivera están repletos de referencias a la perfecta simbiosis entre Iglesia y Falange en materia de educación de las mujeres. Asimismo, todas las leyes y reformas de la enseñanza media y primaria contienen constantes referencias a la preeminencia y al poder de decisión y control de la Iglesia Católica (control doctrinal y también institucional, pues la enseñanza privada religiosa recuperó su hegemonía).

38 En los cursos 1916-1917, 1926-1927 y 1932-1933 no se incluyen los porcentajes de mujeres que se matricularon en las enseñanzas de Practicantes o Matronas. Para el curso 1986-1987 tampoco se incluyen las facultades de nueva creación (Bellas Artes y Psicología). Sirva esta nota también para el gráfico 10.

39 El curso 1932-1933 se incluye como punto de referencia de la etapa republicana. 
las alumnas fue cambiando, variaba según las épocas. En 1917 y 1927, de todas las facultades, Ciencias era donde se matriculaban más mujeres. En 1933, Ciencias y Farmacia se disputaban la primera posición. Entre ambas, sumaban un $51 \%$ del total de matrículas femeninas. En época franquista, en plena posguerra, Farmacia tomó el relevo a Ciencias, que descendió hasta la tercera posición. En 1957, dos terceras partes de las universitarias optaban por estudiar Farmacia o bien Filosofía y Letras. A partir de ahí, en 1967, 1977 y 1987, Filosofía y Letras fue la opción más escogida por las mujeres. En este siglo, la carrera de Filosofía y Letras pasó de ser una opción minoritaria entre las mujeres (en 1917, entre las preferencias de elección ocupaba la cuarta posición, un 3\%) a ser la facultad de destino de casi la mitad de la población femenina universitaria a finales de siglo (un 47\%).

Durante este proceso de institucionalización de la facultad de Filosofía y Letras como la más escogida entre las mujeres, las otras carreras también modificaron sus dinámicas de crecimiento interno. Antes de la dictadura franquista, primero Derecho y luego Medicina fueron facultades que iban alcanzando más popularidad entre las alumnas: en 1933 un 17\% elegía Derecho y un $13 \%$ Medicina. La década siguiente ambas facultades perdieron fuelle, hasta registrar tan solo un $3 \%$ y un $4 \%$ de alumnas respectivamente. Tuvieron que pasar más de 30 años para recuperar los porcentajes de preguerra: Medicina en 1977, Derecho en 1987.

Llegados a este punto parece difícil negar que las tendencias de crecimiento de la población femenina universitaria se vieron alteradas con la instauración del Nuevo Estado. Es así aun siendo consciente de que los datos anteriores a la Guerra Civil son limitados y aceptando la condición de que quizás las dinámicas de entrada y redistribución de las mujeres en la universidad durante el primer tercio del siglo no tuvieron tiempo de consolidarse.

En algunas disciplinas científicas, las alteraciones respecto a las herencias recibidas - las tendencias de crecimiento - fueron positivas y continuistas. En este sentido, el nuevo régimen escogió aquellas dinámicas de facultad que consideró compatibles con sus principios ideológicos y las fomentó. En otros casos, la intervención de las nuevas autoridades franquistas frenó o truncó la dinámica histórica anterior. A partir de la descripción de la evolución de las preferencias de estudio de las mujeres 
hecha unas líneas más arriba, se pueden identificar fácilmente qué facultades se pueden incluir en el primer grupo - les dieron continuidad y explotaron la herencia recibida - y cuáles en el segundo - frenaron el desarrollo histórico que se podía intuir-.

En esta doble coyuntura es donde se debe ubicar el crecimiento lento pero sostenido de la presencia femenina en la universidad franquista. Hizo furor la retórica franquista de que las mujeres eran de letras y los hombres de ciencias..$^{40}$ Pero esta (falsa) idea, que ha llegado hasta nuestros días, no puede argumentarse con evidencias históricas. A partir de los datos presentados, todo indica que fue durante la dictadura que este discurso, que se promovió conscientemente y se repitió hasta la saciedad, consiguió impregnar todas las capas de la sociedad. El mensaje fue interiorizado colectivamente. ${ }^{41}$

Tan solo como referencia para comparar, en el gráfico 10 se recogen los datos relativos a las preferencias de estudio del alumnado masculino. A diferencia de la tendencia descrita para las universitarias, los alumnos varones tendían a distribuirse de forma más o menos equilibrada entre

40 Sobre esta cuestión, resulta de gran interés el reciente artículo de Canales (2018). Compartimos ampliamente la idea de que «las mujeres históricamente han preferido estudiar carreras de letras, los hombres ciencias» es un "cliché" ("gender stereotype") sin fundamentos. No obstante, la diferencia de pareceres surge en evaluar si el régimen franquista alteró este patrón. Canales sostiene que con la instauración del nuevo régimen no se alteró que las universitarias se decantaran por carreras de ciencias, el cambio no se produciría hasta los años 60 (Canales 2018, 43). Desde nuestro punto de vista, ciertamente el cambió radical en las preferencias de estudio de las mujeres se dio en la década de los 6o, pero consideramos que no se puede minorizar el gran aumento de matrículas en la facultad de Filosofía y Letras y la disminución de matrículas en Medicina que se produjo durante las décadas de los años cuarenta y cincuenta. Es decir, quizás se debería añadir un matiz: con la instauración del franquismo las mujeres seguían prefiriendo - como opción mayoritaria - las carreras de ciencias (si eran Ciencias o Farmacia, pero no Medicina), pero paralelamente la facultad de Letras fue adquiriendo mayor protagonismo. El desacuerdo surge en considerar que en las dos primeras décadas de la dictadura no se producen cambios en las preferencias. Los cambios no son de la envergadura de los que tienen lugar en los años 6o, pero algo se mueve, no es una continuación exacta de la situación de preguerra.

41 Así lo indican todas las mujeres entrevistadas hasta la fecha (mujeres que nacieron entre 1930 y 1950 y que estudiaron en la universidad durante la dictadura, y algunas consiguieron hacer carrera académica). Las mentalidades y los esquemas socioculturales solo se pueden recuperar a través del diálogo y la rememoración. El conjunto de entrevistas realizadas constituye el fondo oral Mujeres y Universidad Franquista, proyecto cofinanciado por el CEFID-UAB y el Ajuntament de Barcelona. Se puede consultar la presentación oficial de dicho fondo en el siguiente enlace: https://vimeo. com/149390584. 
todas las facultades (los porcentajes siempre se movían entre un $20 \%$ y un 30\%). Las excepciones a la dinámica general se daban en Farmacia y en Filosofía y Letras, que siguieron trayectorias un tanto peculiares. La facultad de Farmacia, a medida que se avanzaba en la cronología, perdía popularidad entre la población masculina. Cada vez menos hombres elegían estudiar Farmacia. Por el contrario, en Filosofía y Letras pasó el fenómeno inverso: siendo la elección menos popular entre los alumnos en 1917, en 1987 se situó en primera posición: era la carrera más solicitada entre los hombres. 


\section{Gráfico 9. Reparto porcentual del alumnado femenino entre las distintas facultades de la UB por cursos académicos (1917-1987)}

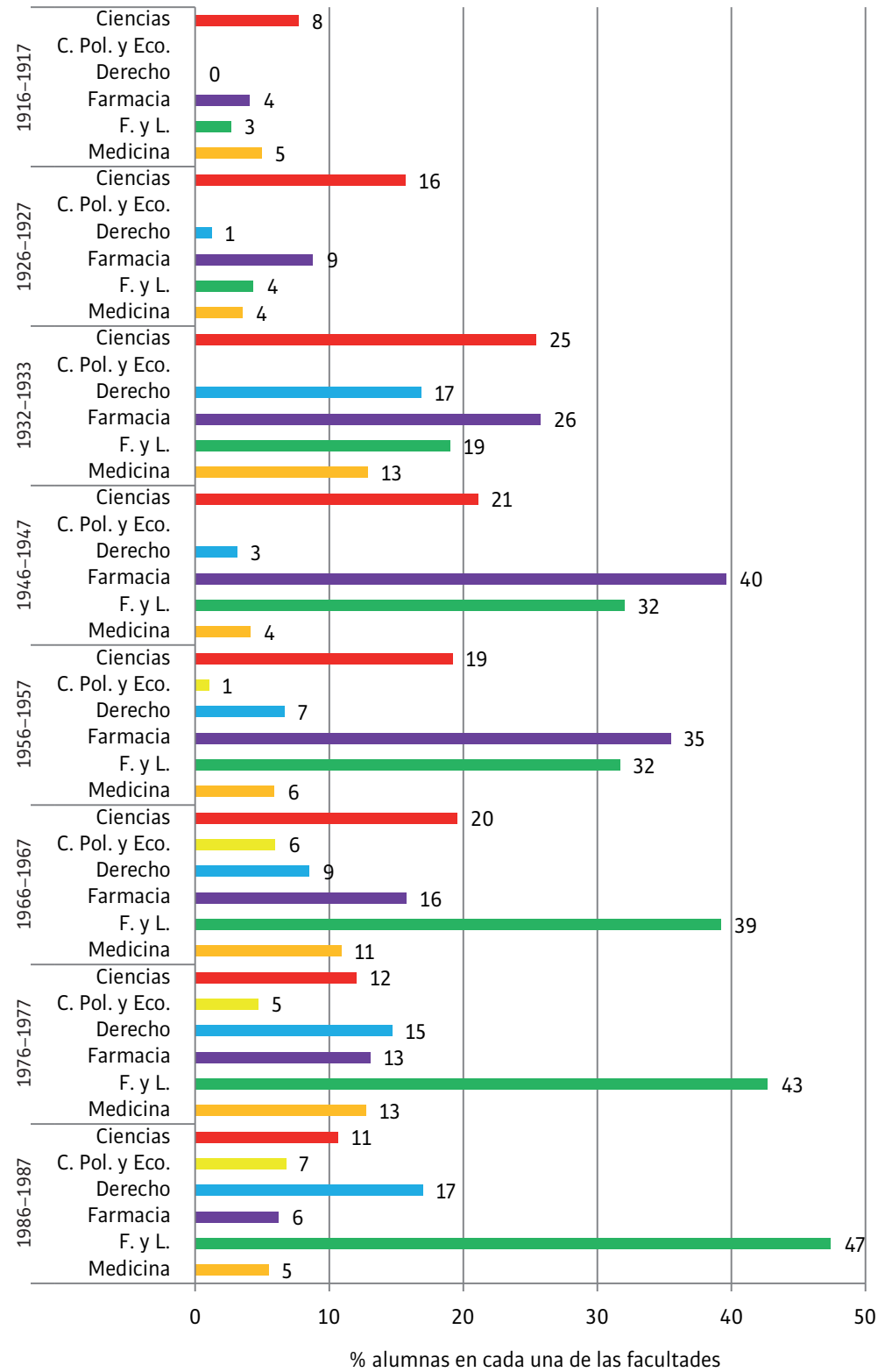

Fuente. Anuario Estadístico de España, Fondo INEbase/Historia. Elaboración propia. 
Gráfico 10. Reparto porcentual del alumnado masculino entre las distintas facultades de la UB por cursos académicos (1917-1987)

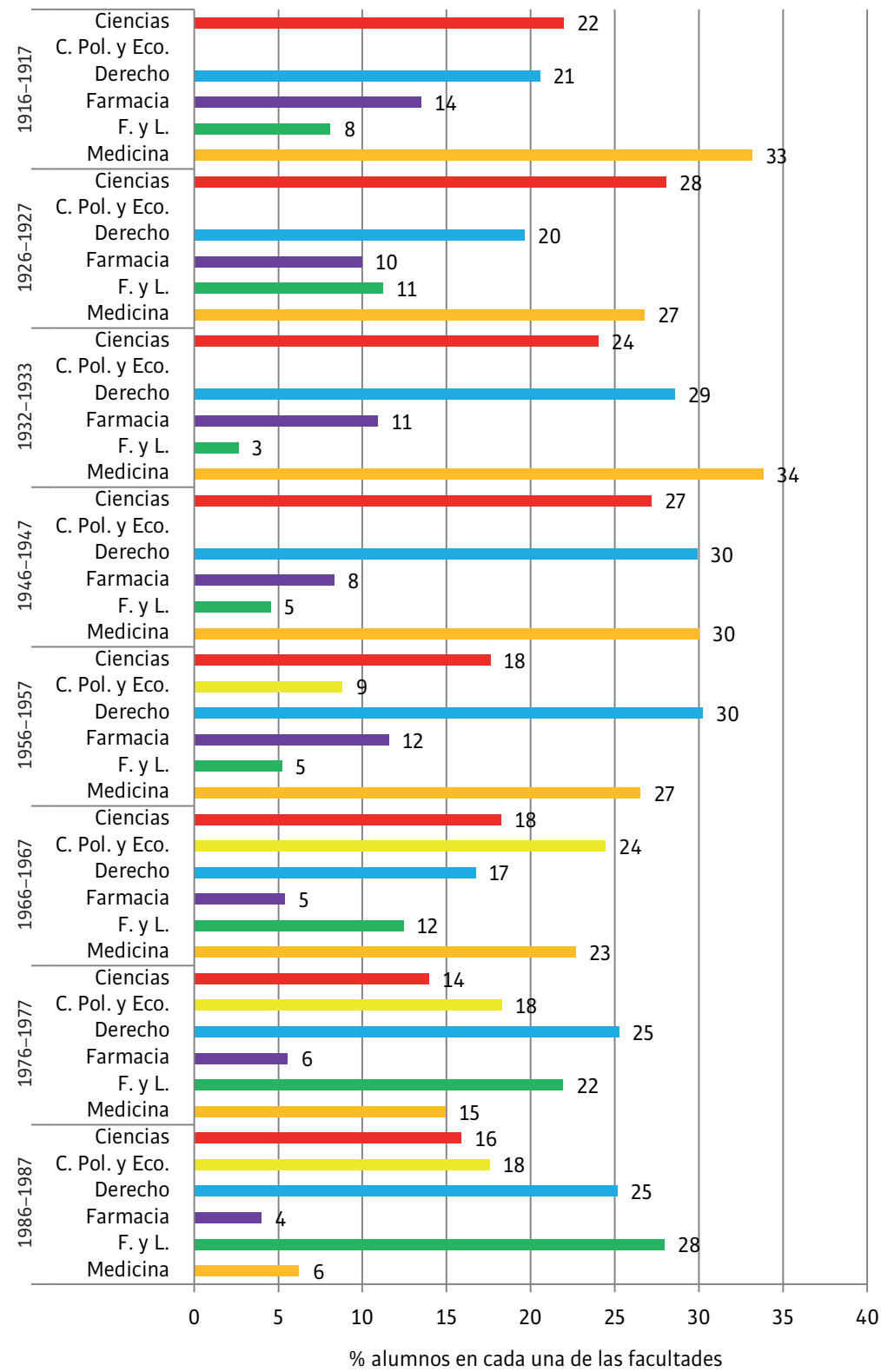

Fuente. Anuario Estadístico de España, Fondo INEbase/Historia. Elaboración propia. 
En cuanto al profesorado se refiere, la gran pregunta es saber la relación existente entre los datos relativos a las matrículas y las facultades donde aparecen las primeras profesoras. Al tratarse de un fenómeno excepcional (en 1957 la proporción de mujeres entre el profesorado era tan solo un $10 \%$, 70 profesoras), las interpretaciones derivadas sobre este colectivo durante el primer franquismo son únicamente indicativas de una tendencia intuida. ${ }^{42}$

Siguiendo el mismo procedimiento que el utilizado para las alumnas, en el gráfico 11 se pueden observar los porcentajes sobre el reparto de las profesoras entre las distintas facultades en dos cursos académicos: 1947-1948 y 1956-1957. Tomando estas dos referencias podemos comparar cómo se repartían las alumnas (gráfico 9) y las profesoras (gráfico 11) entre las distintas facultades.

Gráfico 11. Reparto porcentual de las mujeres profesoras entre las distintas facultades de la Universidad de Barcelona (cursos de 1947-1948 a 1956-1957)

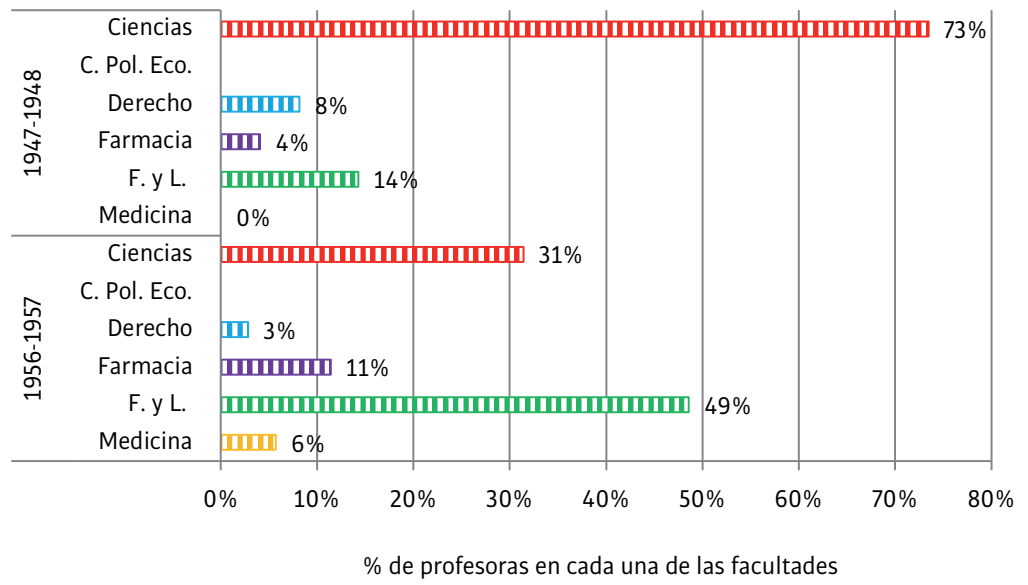

Fuente. Estadístico de la enseñanza España, INE. Elaboración propia.

42 De nuevo hay que recordar las dificultades para reconstruir la plantilla docente (divergencias numéricas entre fuentes documentales y valores inverosímiles o sobredimensionados). 
En el curso $1947-1948,43$ las 49 profesoras registradas estaban repartidas de la siguiente manera (por orden de mayor a menor cantidad): 36 en Ciencias (un 73\%), 7 en Filosofía y Letras (un 14\%), 4 en Derecho (un 8\%) y 2 en Farmacia (un 4\%). En Medicina no había presencia femenina. En cuanto al estamento estudiantil, en 1946-1947 las alumnas se concentraban mayoritariamente en Farmacia (un 40\%) y en Filosofía y Letras (un 32\%), seguido de Ciencias (un 21\%), Derecho (un 3\%) y Medicina (un $4 \%)$. Al comparar el orden y las proporciones se constata que alumnas y profesoras se repartían de formas distintas y no correlativas entre sí. Si se realiza el mismo ejercicio comparativo entre alumnas y profesoras para el curso 1956-1957, la variabilidad y la no-correspondencia automática se confirman.

Obviamente, para que hubiese profesoras en una facultad primero debía haber alumnas. Pero no parece que este fuese el único factor que intervenía. La hipótesis de trabajo que se plantea es que las motivaciones y los aspectos que se tenían en cuenta a la hora de elegir qué carrera estudiar eran distintos - aunque no excluyentes - a las razones que intervenían en el momento en que una licenciada decidía o se planteaba probar suerte profesionalmente en la universidad e iniciar una posible carrera académica. ${ }^{44}$

Tras los escombros de la Guerra Civil, las nuevas autoridades franquistas llegaron al poder para hacer la contrarrevolución, imponer su ideología y aplicar reformas en todos los ámbitos de acuerdo con los nuevos postulados nacional-católicos. A diferencia de lo que sucedió en otras esferas, en materia educativa, Iglesia y Estado siempre fueron juntos de la mano, y en esa nueva cruzada educativa la mujer, tal y como la concebían (un objeto homogéneo y complementario al hombre), tenía todas las de perder. De repente, las españolas pasaron de vivir una — breve- época

43 No disponemos de datos del curso anterior.

44 Precisamente, el elemento a objetar a la tesis defendida por Sanchidrián respecto a la evolución del profesorado universitario femenino es la unicidad de su razonamiento. «En general, el porcentaje de profesoras correlaciona altamente con el de alumnas: donde hay más alumnas hay también más profesoras y al revés, aunque las cifras porcentuales son inferiores en el caso de las docentes» (Sanchidrián Blanco 2008, 235). Entre otros motivos, se trata de una visión un tanto determinista: habrá profesoras donde haya alumnas primero. Esta lógica, sin embargo, no se cumplió en el posterior desarrollo de las plantillas docentes universitarias. 
dorada de cambios y nuevas esperanzas, a verse recluidas en un mundo interior, pequeño y oscuro. En ese contexto, las universitarias tampoco escaparon de la debacle. Si bien el franquismo no significó un retroceso en términos absolutos de la presencia femenina en la enseñanza universitaria, sí ralentizó las dinámicas de crecimiento que se intuían en la década anterior. Con la dictadura, empezaba una etapa en que el rasgo más definitorio era el estatismo. Una situación que no empezó a cambiar hasta finales de los sesenta, inicios de los setenta.

\section{Bibliografía}

Alted Virgil, Alicia. 1986. «La mujer en las coordenadas educativas del régimen franquista», 425-438. En M.C. García-Nieto, ed., Ordenamiento jurídico y realidad social de las mujeres: siglos XVI a XX. Madrid: Seminario de Estudios de la Mujer Universidad Autónoma de Madrid.

Ballarín Domingo, Pilar. 2001. La educación de las mujeres en la España contemporánea (siglos $X I X-X X)$. Madrid: Editorial Síntesis.

- 2010. «Entre ocupar y habitar. Una revisión historiográfica sobre mujeres y Universidad en España». Arenal. Revista de Historia de Mujeres 17/2: 223-254. http:// revistaseug.ugr.es/index.php/arenal/article/view/1450/1618.

Bohigas Gavilanes, Francisca. 1947. ¿Qué profesión elegir? Guía de profesiones femeninas. Madrid: Mayfe.

Canales, Antonio Fco. 2012. «Little intellectuals. Girls’ academic secondary education under Francoism: projects, realities and paradoxes». Gender and Education 24/4: 375-391. doi: https://dx.doi.org/10.1080/09540253.2012.674494.

- 2018. «Women, university and science in the twentieth-century Spain». History of Education 47/1: 36-57. doi: https://doi.org/10.1080/0046760X.2017.1378384.

Carbajo Vázquez, Judith. 2003. «Mujeres y educación (1965-1975)». En J. Cuesta Bustillo, ed., Historia de las mujeres en España: Siglo Xx. Madrid: Instituto de la Mujer.

Castán Tobeñas, José. 1955. La condición social y jurídica de la mujer. Madrid: Instituto Editorial Reus.

Centro Nacional de Investigación y Documentación Educativa (C.N.I.E.). 1988. La presencia de las mujeres en el sistema educativo. Madrid: Ministerio de Cultura Instituto de la Mujer.

Claret Miranda, Jaume. 2006. El atroz desmoche. La destrucción de la universidad española por el franquismo, 1936-1945. Barcelona: Crítica.

Cuesta Bustillo, Josefina, María Luz de Prado Herrera y Francisco Javier Rodríguez, eds. 2015. ¿Mujeres sabias? Mujeres universitarias en España y América Latina. Limoges: Pulim. 
De Borja i Solé, Maria. 1983. Carreras y sexos: nueva versión, estudio comparativo de dos generaciones. Barcelona: Hogar del Libro.

Del Val Valdivieso, María Isabel, y Esther Martínez Quinteiro, eds. 2015. Comiendo del fruto prohibido: mujeres, ciencia y creación a través de la historia. Barcelona: Icaria.

Di Febo, Giuliana. 2006. «La Cuna, la Cruz y la Bandera”. Primer franquismo y modelos de género», 217-237. En Isabel Morant Deusa, dir., Guadalupe Gómez-Ferrer, Gabriela Cano, Dora Barrancos y Asunción Lavrin, eds., Historia de las mujeres en España y América Latina IV: Del siglo XX a los umbrales del XXI. Madrid: Ediciones Cátedra.

Flecha García, Consuelo. 1996. Las Primeras universitarias en España, 1872-1910. Madrid: Narcea.

— 2010. «Profesoras en la Universidad. El tránsito de las pioneras en España». Arenal: Revista de Historia de Mujeres 17/2: 255-297. http://revistaseug.ugr.es/index. php/arenal/article/view/1451/1619.

— . 2011. «Por derecho propio universitarias y profesionales en España en torno a 1910». Tabanque. Revista Pedagógica 24: 157-174.

_ 2015a. «Ganando espacios en la universidad española en la primera mitad del siglo XX», 103-135. En María Isabel del Val Valdivieso y Esther Martínez Quinteiro, eds., Comiendo del fruto prohibido: mujeres, ciencia y creación a través de la historia. Barcelona: Icaria.

- 2015b. «La educación franquista y las mujeres», 219-253. En Antonio F. Canales Serrano y Amparo Gómez Rodríguez, eds., La larga noche de la educación española. El sistema educativo español en la posguerra. Madrid: Biblioteca Nueva.

Gallego Méndez, María Teresa. 1983. Mujer, falange y franquismo. Madrid: Taurus.

García de Cortázar Nebreda, María Luisa, y María Antonia García de León. 1997. Mujeres en minoría: una investigación sociológica sobre las catedráticas de universidad en España. Madrid: Centro de Investigaciones Sociológicas.

García de León, María Antonia. 2002. Herederas y heridas: sobre las élites profesionales femeninas. Valencia: Universitat de València.

García de León, María Antonia, y María Luisa García de Cortázar Nebreda. 2001. Las académicas: profesorado universitario y género. Madrid: Instituto de la Mujer Ministerio de Trabajo y Asuntos Sociales.

Magallón Portolés, Carmen. 2010. «Las mujeres que abrieron los espacios de las ciencias experimentales para las mujeres, en la España del primer tercio del siglo xx». Arenal. Revista de Historia de Mujeres 17/2: 319-347. http://revistaseug.ugr.es/index.php/ arenal/article/view/1453/1621.

Martín Zúñiga, Francisco. 1998. «Estructura del profesorado universitario en la legislación franquista (1939-1969)», 564-573. En AA.DD., La Universidad en el siglo Xx: España e Iberoamérica. X Coloquio de Historia de la Educación (Murcia, 21-24 de septiembre de 1998). Murcia: Universidad de Murcia - Departamento de Teoría e Historia de la Educación.

Matilla Quiza, María Jesús. 2015. «Las primeras doctoras universitarias en España. La Facultad de Filosofía y Letras de Madrid (1882-1954)», 83-122. En Josefina Cuesta 
Bustillo, María Luz de Prado Herrera y Francisco Javier Rodríguez, eds., ¿Mujeres sabias? Mujeres universitarias en España y América Latina. Limoges: Pulim.

Molinero, Carme. 1998. «Mujer, franquismo, fascismo: La clausura forzada en un "mundo pequeño"». Historia Social 30: 97-117.

Montoro Romero, Ricardo. 1981. La Universidad en la España de Franco, 1939-1970: un análisis sociológico. Madrid: Centro de Investigaciones Sociológicas.

Pando Ballesteros, María de la Paz. 2015. «La teorización sobre el alumnado femenino en la universidad franquista a la luz del caso de Salamanca», 263-299. En Josefina Cuesta Bustillo, María Luz de Prado Herrera y Francisco Javier Rodríguez, eds., ¿Mujeres sabias? Mujeres universitarias en España y América Latina. Limoges: Pulim.

Pemartín Sanjuán, José. 1937. ¿Qué es «lo nuevo»...? Consideraciones sobre el momento español presente. Sevilla: Cultura Española.

Pintos Barral, Xoana. 2016. «As mulleres nos estudos experimentais na Universidade de Santiago: 1910-1960». Tesis doctoral, Universidad de Santiago de Compostela. http:// hdl.handle.net/10347/14763.

Poy Castro, Raquel. 2009. «Mujeres y universitarias: historia de un desencuentro en la universidad española contemporánea», 357-381. Revista del Seminario Interdisciplinar de Estudios de las Mujeres de la Universidad de León 4: 357-381. doi: https://dx.doi.org/10.18002/cg.voi4.3818.

Presidencia del Gobierno, INE. 1958. Estadística de la Enseñanza en España. Curso 19551956. Madrid: INE.

Reparaz de la Serna, Guillermo. 2015. «Base de datos para el estudio de la mujer en la Facultad de Farmacia de la Universidad de Madrid en la España autárquica (19381959)». Tesis doctoral, Universidad Complutense de Madrid. https://eprints.ucm. es/30624/1/T36140.pdf.

Roca i Girona, Jordi. 2003. «Esposa y madre a la vez: construcción y negociación del modelo ideal de mujer bajo el (primer) franquismo», 45-66. En Gloria Nielfa Cristóbal, ed., Mujeres y hombres en la España franquista: sociedad, economía, política, cultura. Madrid: Universidad Complutense.

Rodríguez López, Carolina. 2013. «Del pupitre a la tarima. Mujeres, ciencia y universidad en España en el primer tercio del siglo xx. Línieas de trabajo y debates», 283-312. En Rosa María Capel Martínez, coord., Presencia y visibilidad de las mujeres: recuperando historia. Madrid: Abada.

Ruiz Franco, Rosario. 2007. «La situación jurídica de las mujeres en el tardofranquismo: avances y permanencias», 329-346. En Pilar Amador Carretero y Rosario Ruiz Franco, eds., La otra dictadura: el régimen franquista y las mujeres. Madrid: Instituto de Cultura y Tecnología - Universidad Carlos III de Madrid.

Saavedra-Mitjans, Helena. 2016. «Mujeres y universidad franquista: trayectorias vitales, académicas y profesionales». Tesis doctoral, Universitat Autònoma de Barcelona. http://hdl.handle.net/10803/391036.

Sanchidrián Blanco, María del Carmen. 1999. «El modelo de bachillerato universitario de 1938: la difícil incorporación de las mujeres a este nivel», 587-604. En Julio Ruiz Berrio, ed., La Educación en España a examen (1898-1998): jornadas nacionales en 
conmemoración del centenario del noventayocho. Madrid/Zaragoza: Ministerio de Educación y Cultura / Instituto Fernando El Católico - Diputación de Zaragoza. Sanchidrián Blanco, María del Carmen. 2008. «Estudios universitarios y ejercicio profesional de las mujeres en el franquismo», 217-248. En Carmen Jiménez Fernández y María Gloria Pérez Serrano, eds., Educación y género: el conocimiento invisible. Madrid: UNED.

Santesmases, María Jesús. 200o. Mujeres Científicas en España, 1940-1970:

Profesionalización y modernización social. Madrid: Instituto de la Mujer - Ministerio de Trabajo y Asuntos Sociales.

Universitat de Barcelona. 1950. La Universidad de Barcelona 1950. Barcelona: UB. . 1956. Universidad de Barcelona 1956. Barcelona: UB.

Vázquez Ramil, Raquel. 2012. Mujeres y educación en la España contemporánea: la Institución Libre de Enseñanza y la Residencia de Señoritas de Madrid. Madrid: Akal. 